\title{
ERSTER ABSCHNITT: $1842-1858$ \\ Von der Gründung des Unternehmens \\ bis zum Verkauf des Sortiments
}

$\mathrm{D}$

ie Familie Springer stammt aus Frankfurt an der Oder, wo

Julius Springers Großvater gleich nach dem Sicbenjähri-

Herkunft der Familie.

gen Krieg (1764) eine Handelskonzession erhalten hatte. Springers Vater Isidor (1771-1836) war 1812 in Berlin ansässig geworden, hatte am 15.11.1813 das Bürgerrecht und 1815 eine Konzession als Kaufmann - die entschieden mehr bedeutete als die eines > Händlers $<$ - bekommen. Im gleichen Jahr heiratete er Marianne Friedlaender (1788-1817), die aus einer zu Wohlstand gelangten Berliner Familie stammte. Julius, ihr einziges Kind, wurde am 10.5.1817 in Berlin geboren. Die Mutter starb an Kindbettfieber, und der Junge wurde zunächst der Großmutter Friedlaender zur Obhut übergeben.

Noch nicht drei Jahre alt, wurde Springer der Cauer'schen Erziehungsanstalt anvertraut. Dieses Berliner Internat hatten 1818 zehn Pädagogen gegründet, die von den Vorlesungen Johann Gottlicb Fichtes so stark beeindruckt waren, daß sie nach Yverdon am Genfer Sec zogen, um sich von Pestalozzi selbst unterweisen zu lassen. Im Mittclpunkt des Lehrplans standen Griechisch, Mathematik und Musik. Daneben pflegte man noch Zeichnen und auch Turnen, das seit 1820 aus Gründen der Staatssicherheit in der Öffentlichkeit verboten war. Bei der Erziehung legte man besonderen Wert darauf, sden Zögling in seinem sittlichen, intellektuellen und technischen Vermögen zu beleben und zu cntwickeln« [LASSAHN]. Die Gemeinschaft von Lehrern und Schülern sollte diesen für ihr künftiges Leben im Beruf und in der Gesellschaft zum Vorbild werden. Springer hat sich stets mit Dankbarkeit an seine erste Schule erinnert.

Im Oktober $1829 \mathrm{kam}$ er in die Untertertia des >Gymnasiums zum Grauen Kloster<, das er zu Ostern 1832 nach Abschluß der Untersekunda mit einem vorzüglichen Zeugnis verließ, um eine Lehre in der Enslin'schen Buchhandlung, Breite Straße 23, anzutreten.

Q pringers Lehrherr, Georg Wilhelm Ferdinand Müller Lehr-and Wanderjahre (1806-1875)', erkannte sehr bald dic besonderen geistigen Fähigkeiten seines Zöglings und förderte dessen Ausbildung 


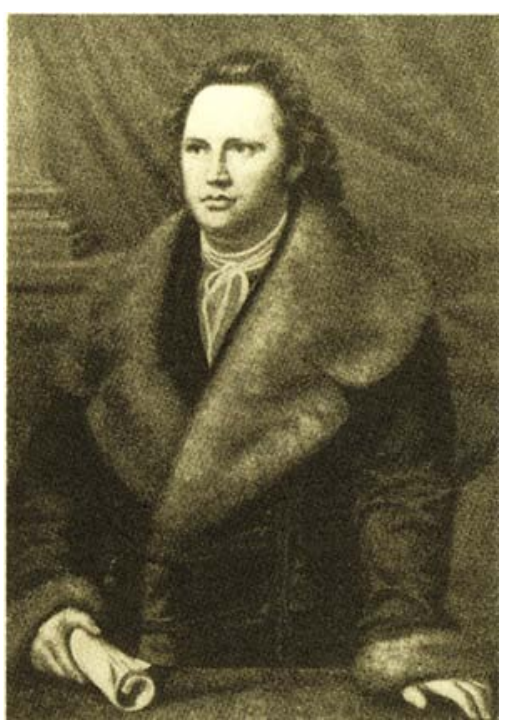

1: Ludwig Cauer (1792-1834) grändete 1818 mit einigen Freunden eine Erziehangsanstalt in Berlin, Münzstraße 21, in die Julius Springer schon 1820 gegeben wurde und in der er bis 1829 verblieb, als die Schule schon nach Charlottenburg in die Berliner Straße verlegt worden war. Das Schulgeld betrug bei seinem Abgang jährlich immerhin 650 Taler einschließlich Halbpension. nach Kräften. War es schon eine Auszeichnung, daß Müller seinen Lehrling bereits 1835 zur Leipziger Messe mitnahm, so ist es wohl im Buchhandel recht ungewöhnlich, daß sich ein Prinzipal und sein früherer Lehrling ein Leben lang auf das engste kollegial verbunden bleiben. Offenbar hat es das gute Verhältnis nicht trüben können, daß Springer sich 1842 einige Häuser yon seiner Lehrfirma entfernt etablierte. Konkurrenzneid gab es zwischen Müller und Springer nicht. Später bekannte Müller, »daß ihm selten im Leben ein Mann vorgekommen, der so ernst wie Springer bemüht gewesen [ist], unablässig an sciner eigenen Besserung und Vervollkommnung zu arbeiten«, und wie sehr ihm diese ausdauernde »Arbeit der Selbsterziehung " gelungen sei [KAISER: 4]. Neben den beruflichen entstanden später auch enge familiäre Kontakte, denn 1890 heiratete eine Enkelin Müllers Springers drittältesten Sohn Ernst (1860-1944).

An dicse außerordentlich fruchtbare Lehrzeit schlossen sich vier buchhändlerische Wanderjahre an. Durch die Vermittlung von Friedrich Volckmar, Müllers Leipziger Kommissionär, der Springer auf der Messe kennen und schätzen gelernt hatte, bekam er eine Gehilfenstellung bei Salomon Höhr in Zürich, einem offenbar recht schwierigen Berufsgenossen, zu dem Springer aber cin so gutes Verhältnis gewann, daß er ihn bei seinen späteren Aufenthalten in der Schweiz stets gern besuchte [MS: $5 \mathrm{f}.]^{2}$.

Am 6.3.1836 hatte Springer seine Reise in die Schweiz zu Fuß angetreten. Ein Tagespensum von acht bis neun Stunden war ihm nicht zuviel [GotThEs: 17.6.1854] ${ }^{3}$. Er wanderte über Frankfurt, Heidelberg und Straßburg und machte hier wie auch andernorts sicherlich eine längere Rast. Mitte April erreichte er Zürich und fand dort die Nachricht vor, daß sein Vater am 30.3.1836 in Berlin gestorben sei. Mit noch nicht 19 Jahren war Julius Springer Waise. In Berlin wurde ein Vormund für ihn bestellt.

In Zürich wurde Springer sehr bald mit der Schweizer Lebensweise vertraut. Hier gab es keinen Adelsstolz, kein omnipotentes Militär, und die Verwaltung, »die Burcaucratie«, diente dem Bürger. Das Leben in Zürich hat Springers Sinn für demokratische Lebensformen nachdrücklich geprägt. Hier hatte er »reichlich Gclegenheit, sein Gefühl für Freiheit, Recht und Öffentlichkeit auszubilden« [MS: 6]. Der Kanton Zürich hatte sich 1831 cine demokratische Verfassung gegeben, wodurch die Stadt schon damals eine starke Anzichungskraft für politische Flüchtlinge hatte. Hier lernte Springer außer Georg Herwegh auch Georg Büchner kennen, in dessen Zimmer er nach Büchners Tod (19.2. 1837) zog. Das Haus in der Steingas- 
se, heute Spicgelgasse 12, gehörte dem liberalen Regierungsrat und späteren Zürcher Bürgermeister Dr. med. Ulrich Zehnder, der manchem politischen Flüchtling Zuflucht bot.

Nach zwei Zürcher Jahren ging Springer im Frühjahr 1838 als Gehilfe zu Paul Neff nach Stuttgart, der ein Sortiment von bedeutendem Umfang führte. Neff war ein besonders unternehmungsfreudiger Buchhändler, der sich auch verlegerisch betätigte und zum Begründer des Stuttgarter Kommissionswesens wurde. Die hier gesammelten Erfahrungen sollten Springer später in scinem eigenen Unternehmen von Nutzen sein. Auch die Kenntnis der Usancen des süddeutschen Buchhandels, die sich von denen Leipzigs und Norddeutschlands damals noch unterschieden, kamen ihm später zugute. In diese Stuttgarter Zcit fallen auch Springers erste Pläne, sich als Buchhändler selbständig zu machen. Angeregt von seinem Zürcher Prinzipal Höhr und ermutigt durch Friedrich Volckmar, dachte Springer zunächst daran, sich in der französischen Schweiz zu etablieren.

Im Sommer 1839 gab Springer seine Stellung bei Neff auf und begab sich für sechs Wochen auf eine Erkundungsfahrt nach Lausanne und Genf. Doch die Auskünfte waren nicht ermutigend: In Lausanne beanspruchten die Kunden, insbesondere die Bibliotheken, sehr lange Zahlungsziele und erwarteten darüber hinaus noch einen Nachlaß von $10-15 \%$ auf alle Rechnungen. Wenn überhaupt, so war die Etablierung nur mit einem ganz erheblichen Kapital möglich, über das Springer nicht verfügen konnte.

Springer war von seinem Lausanner Plan zwar schon weitgehend abgerückt, doch unternahm er trotzdem noch eine Reise nach Paris, wo er am 17.9.1839 eintraf. Am 6.10.1839 trat er eine Stellung in der Buchhandlung Brockhaus \& Avenarius an, die ihm ebenfalls Friedrich Volckmar vermittelt hatte. Hier wollte Springer die besonderen Bedingungen des französischen Buchhandels kennenlernen. Briefliche Äußerungen ${ }^{4}$ lassen erkennen, daß er sich in Paris nicht sonderlich wohl gefühlt hat. Zwar bezauberte ihn dic Stadt, doch er fand wohl nicht den rechten Kontakt. Obwohl Springer nur ein Vierteljahr in Paris blicb, war dic Zcit für ihn fachlich ergiebig. Hiervon zeugen auch seine Berichte für die >Süddeutsche Buchhändler-Zeitung $<$, in denen er über den französischen Markt und seine Arbeitsbedingungen berichtete. Den ersten schrieb er noch im September 1839, also kurz nach seiner Ankunft. Insbesondere argumentierte Springer gegen die Nachdrucke französischer Bücher, mit denen belgische Verleger den französischen Markt überschwemmten. Und er berichtete ausführlich über einen

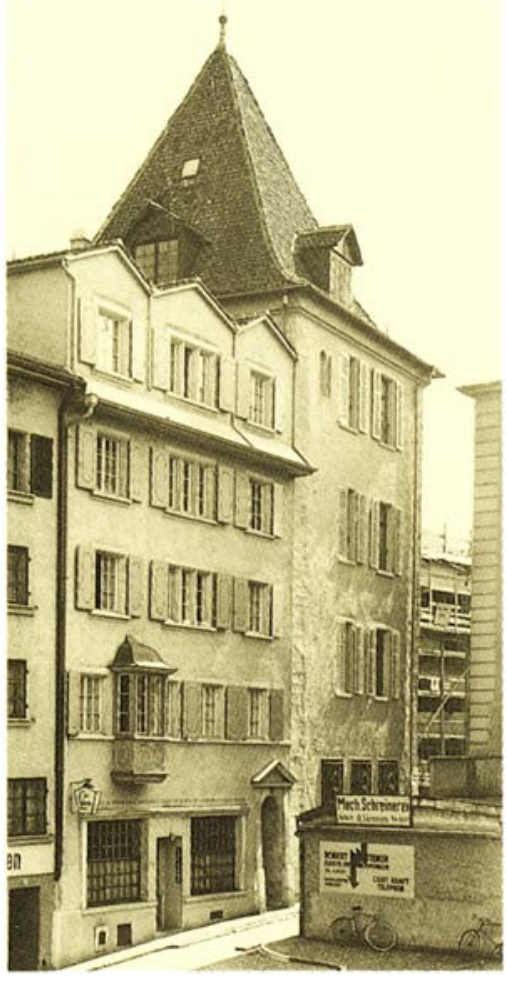

2: Während seines Zürcher Aufenthalts bezog Springer im Haus des liberalgesinnten Arztes und Kommunalpolitikers Ulrich Zehnder (Spiegelgasse 12) das Zimmer, in dem Georg Büchner bis zu seinem Tode gewohnt hatte. 
3: August Böckh hatte als Rektor der Universität die Geburtstagstede auf den König zu halten. Es war Springers Ehrgeiz, den angesehenen Altphilologen für seinen Verlag zu gewinnen. Un die Gunst des Königs buhlte er nicht, auch wenn ihm dessen Geneigtheit nicht wnlieb sein konnte.

\section{Mede}

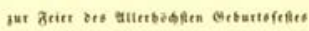

Sriner Alaịestàt ơcs Alōnigs

\section{Frièrich \$Bilbelm oes 2 Sierten}
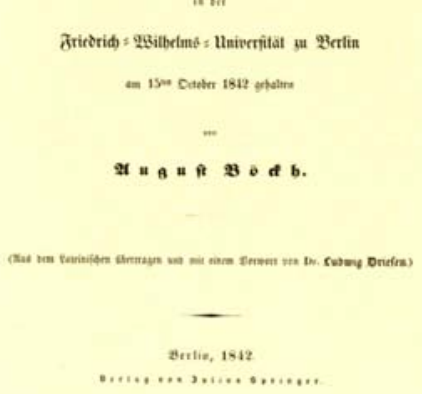

Prozeß, den Balzac als Präsident der société des Gens de Lettres< erfolgreich gegen cine Zeitschrift führte, die Arbeiten französischer Autoren ohne Genehmigung nachgedruckt hatte.

Im Winter 1839/40 kehrte Springer über Belgien nach Berlin zurück. Das Schweizer Projekt hatte er aufgegeben und war nun entschlossen, sich in Berlin zu etablieren. Um wieder mit dem Markt vertraut zu werden, nahm er zunächst eine Stellung in der Buchhandlung von E.H.Jonas (Werderstraße 11) an, cinem weitläufigen Verwandten seiner verstorbenen Mutter.

In Berlin hatte sich in den Jahren, während Springer auf Wanderschaft war, manches verändert. Dic Stadt zählte inzwischen etwa 300000 Einwohner, womit ihre Bevölkerung in vier Jahren immerhin um $20 \%$ zugenommen hatte. Auch der Buchhandel befand sich in einer Phase des Aufschwungs, und dies nicht nur in Berlin. Es gab in der Königlichen Haupt- und Residenzstadt etwa 100 buchhändlerische Unternehmen. Die meisten betricben neben dem Sortimentsgeschäft noch einen Verlag, und auch vicle Verlage unterhielten cin Sortiment. Eine Spezialisierung konnte nur wenigen Firmen eine hinreichende Basis sichern, zumal die meisten erst im Laufe der letzten zehn Jahre gegründet worden waren. Manche dieser Firmen würde man heute eher als Buchverkaufsstellen bezeichnen, da sie neben Büchern auch anderes feilboten.

Die Welle der Neugründungen verstärkte sich noch, nachdem Friedrich Wilhelm IV. am 7.6.1840 den Thron bestiegen hatte. Vom neuen König crwartete man ein Ende des bürokratischen Obrigkeitsstaates, und es gab zunächst auch erste Zeichen für eine Liberalisierung: Politische Häftlinge wurden amnestiert und die Zensur gelockert. Jacob und Wilhelm Grimm, 1837 vom König von Hannover des Landes verwiesen (>Göttinger Sieben $<$ ), wurden zu ordentlichen Mitgliedern der Akademie berufen und erhielten eine Lchrbefugnis für die Berliner Universität. Doch Springer ließ sich vom allgemeinen Optimismus nicht mitreißen. Er »gehörte zu den wenigen, damals Verpönten, die in dem König nur einen Schauspieler sahen « [MS: 9f.]. Springer fand seinen Pessimismus bald bestätigt, denn schon 1843 wurden viele der gewährten Freihciten wieder eingeschränkt.

Der weitgereiste junge Buchhändler wurde von den alten Freunden willkommen geheißen, und er schlo $ß$ bald neue Bekanntschaften in den bürgerlichen Kreisen Berlins. »Der hübsche, angenehme junge Mann «[MS: 9], der direkt aus Paris kam und einige Jahre in der damals noch schwer erreichbaren Schweiz gelebt hatte, war in den liberalen Kreisen des vormärz- 
lichen Berlin ein willkommener Gesprächspartner. Aus manchen der in dieser Zeit geknüpften Kontakten sollten später auch Verlagsverbindungen erwachsen.

$\ddot{U}$ ber scine Absicht, ein eigenes Unternehmen zu gründen, äußerte sich Springer ausführlich in einem Brief, den er am 14.2.1842 dem befreundeten Stettiner Buchhändler Léon Saunier ${ }^{5}$ schrieb:

Wenn ich bei meiner Absicht, mich hier zu etablieren, ein schon bestchendes Geschäft ankaufen wollte, so könnte ich nur ein größeres, bedeutenderes, rentierendes im Auge haben: an den Kauf eines kleinen, bei welchem man doch eigentlich nur die Firma bezahlt, könnte ich nicht denken. Ich hoffe, daß meine eigene Firma sich bald im Buchhandel Geltung verschaffen wird. Ich habe daher nochmals alle Verhältnisse genau und aufs sorgfältigste erwogen, Erfahrung und die Umstände zu Rate gezogen und habe dann den festen Entschluß gefaßt, mich hier in Berlin selbst, auf eigenen Füßen stehend, zu etablieren. Ich bin mir meiner Fähigkeiten und meiner Tätigkeit bewußt, ich kenne den hiesigen Platz genau bis in seine kleinsten Details, ich habe eine mehr als ausreichende Bekanntschaft; an Kredit im Buchhandel wird es mir nicht fehlen.

Ich weiß, ich werde in der ersten Zeit mit vielen und bedeutenden Schwierigkeiten zu kämpfen haben, ich hoffe aber, Energie und Kraft genug zu besitzen, sie zu überwinden und vor dem guten Fortgang ist mir nicht bange... Vielleicht schon im Mai oder Juni eröffne ich das Geschäft, zu welchem ich bereits das Lokal (Breite und Scharrnstr.Ecke, im Ebeling'schen Hause) gemietet habe.

Dic $>$ Concession zum selbständigen Betricbe des Buchhandels in hiesiger Residenz hatte Springer schon am 21.1.1842 vom Königlichen Polizei-Präsidium erhalten und hierfür $1 \frac{1}{2}$ Taler als Steuer und Stempelgebühr entrichtet. Dic Konzession verpflichtete Springer, »dic scin Geschäft betreffenden CensurGesetze und polizeilichen Verordnungen, sie mögen bereits ergangen sein oder künftig noch ergehen, bei Vermeidung der darin angedrohten Strafen pünktlich (zu) befolgen $\ll$. Die Zensurgesetze zu akzepticren, entsprach gewiß nicht Springers politischer Einstellung, und wir werden erfahren, daß er noch manchen Ärger mit der Polizei bekommen sollte.

Weiterhin wurde vorausgesetzt, daß der Buchhändler »den Betrieb seines Gewerbes dem Königlichen Gewerbe-SteuerAmte anzuzeigen habe und das städtische Bürgerrecht gewinnen werde «. Letzteres war für ihn offenbar nicht problematisch, denn der Nachweis eines verfügbaren Kapitals von 5000 Talern hiervon wurde $\boldsymbol{u}$.a. die Erteilung des Bürgerrechts abhängig gemacht - konnte Springer wohl erbringen. Der Bürgerbrief 
wurde dann auch mit Urkunde vom 13.4.1842 ausgestellt. Es muß dabei offen bleiben, ob er selbst über eigene Mittel in dieser Höhe verfügte, oder ob er schon mit dem Kapital seines künftigen Sozius' Faundel rechnen konnte. Dieser, ein etwas älterer Bekannter Springers, war wiederholt durch das medizinische Staatsexamen gefallen. Er hatte gerade eine Erbschaft gemacht und beteiligte sich mit 3000 Talern an der Buchhandlung. ${ }^{6}$ Hier oblagen ihm überwiegend Büroarbeiten.

Wichtiger als das noch zu erwerbende Bürgerrecht war es für Springer, den deutschen Verlagen und sicher auch einigen be-

4: "Dem Buchhandlungs-Gehülfen Julius Springer wird die Concession zum selbständigen Betriebe des Buchhandels in hiesiger Residenz hiermit unter der Voraussetzung ertheilt, daj derselbe die sein Geschäft betreffenden CensurGesetze und polizeilichen Verordnungen, sie mögen bereits ergangen sein oder künftig noch ergehen, bei Vermeidang der darin angedrohten Strafen pünktlich befolgen, auch den Betrieb seines Gewerbes dem Königlichen Gewerbe-Steuer-Amte anzeigen und das städtische Bürgerrecht gewinnen werde.

Berlin den 2Iten Januar 1842.«

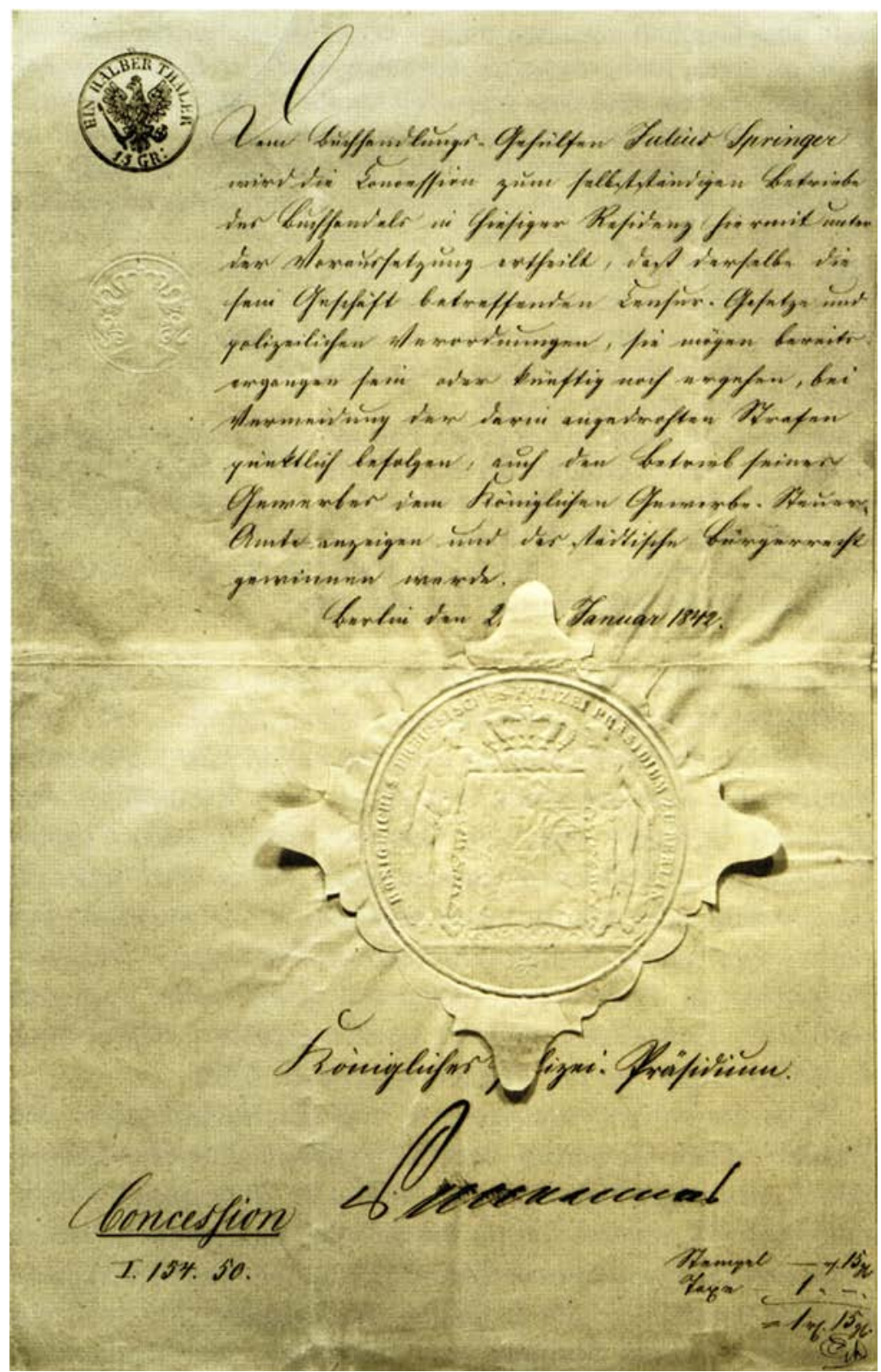




\section{Wermifdate alnzeigen.}

[1906.]

Berlin, ben 6. 2lpril 1842. ergebene 2 (nzeige zu machen, bas id) auf biefigem 9 lase (me $i=$ ner $\mathfrak{B}$ aterftabt) eine $\mathfrak{B u c}$ ) hanblung unter ber Firma:

\section{eróffine.}

\section{Jullins Sprimger}

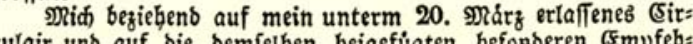

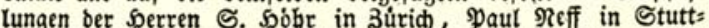
gart, 5 . $\$$. Sonas bier und $\mathcal{F} r$. Bold'mar in \&eipzig, ertaube id mir, meine Bitte: $\mathrm{mir} g$ út $i$ ft ein (sonto ou eroff = nen, mir J̆bre $\Re$ ooa eingufenben unb meinen $\Re a=1$ men auf 3bre seipziger 2 ustieferungslifte zu

fegen, biermit zu roieberbolen.

\$ie aud in meinem (Sirculaire gefagt, werbe id meine Saupttbátigleit bem Sortiment sgefd d f $t$ zuwenben, wet= (hem id) mid) ftets mit befonberer siebe gervibmet babe unb in

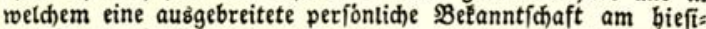
gen Drte unb eine genaue Renntniß aller fonftigen Berbáttniffe

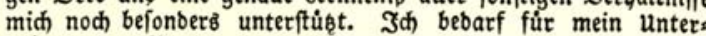
nebmen bes Bertrautens bes $\mathfrak{B u}$ )banbels : inbem id um baf: felbe bitte, fprede id bie Berfiderung aus, bas es mir ftets eine beitige spflidt fein rirb, baffetbe zu reditfertigen. g刃eine Sommiffion bat Şr. Fr. Boldmar in Eeipzig bie Búte gebabt zu úberneb̆men.

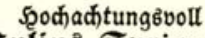
ฐulius Ëpringer. freundeten Sortimentern seine bevorstehende Etablicrung bekannt zu machen. Dies geschah, wie es bei derartigen Anlässen üblich war, durch ein Rundschreiben oder >Circular<. Es trug das Datum vom 20. März. »Meine Haupttätigkeit«, teilte Springer mit, »werde ich zunächst dem Sortiments-Geschäfte zuwenden «. Das >zunächst< läßt schon erkennen, daß er sich keineswegs auf den Sortimentsbuchhandel zu beschränken gedachte. Er hielt es aber wohl nicht für geraten, schon jetzt etwas über seine weitcrhin geplanten Unternehmungen verlauten zu lassen; zu viele Neulinge waren daran gescheitert, daß sie außer mit einem Sortiment auch gleich mit einem Verlag sowie anderen Nebenzweigen aktiv geworden waren und sich hierbei übernommen hatten.

Wie üblich, ließ Springer Referenzen seiner früheren Prinzipale im Circular abdrucken. Höhr empfahl ihn u.a. mit den Worten: »durch seinen unermüdlichen Fleiß, seine Gewandtheit und Tüchtigkeit in jeder Beziehung, war er mir ein treuer Mitarbciter im Geschäfte, wie er durch seinen Charakter nicht minder mein Freund war und es geblieben ist. « Indem er Springer für das, was er bci ihm geleistet hatte, nochmals dankte, bat er seine Kollegen, »Herrn Springer Ihr Vertrauen nicht zu versagen, da in ungewöhnlicher Vereinigung alle Eigenschaften bei ihm vorhanden sind, welche den Erfolg seines Etablissements und die Rechtfertigung Ihres gütigen Vertrauens außer Zweifel stellen. «Paul Neff begnügte sich im wesentlichen mit dem Hinweis, »Herr Julius Springer ist Buchhändler mit Leib und Seele ..., und Besseres weiß ich nicht zur Empfehlung seines jungen Etablissements zu sagen.« Das Zeugnis von Jonas, Springers letztem Prinzipal, wirkt dagegen etwas formell und blaß; vielleicht fürchtete er schon den künftigen Konkurrenten. Volckmar schließlich konnte noch den wichtigen Hinweis geben, »daß mir nämlich Herr Springer die Überzeugung verschaffte, wic seine Geldmittel derart sind, daß sie zu seinem Zwecke mehr als genügend erscheinen «.
5: Den Buchhandel informierte Springer durch eine zweimal wiederholte Anzeige im Börsenblatt, nachdem er schon am 20.3.1842 ein vierseitiges Circular verschickt hatte. 
Eine Anschrift gab Springer nicht an, doch dies war auch kaum nötig, da Buchhändler nur über ihren Leipziger Kommissionär mitcinander verkehrten. An ihn schickten sie ihre Bestellungen für die verschiedenen Verlage, und dieser schickte seinem >Kommittenten ‘ die bestellten Bücher in einer Sammelsendung. Diesen Weg nahmen auch andere, selbst private Mitteilungen. So genügte es also, nur den Leipziger Kommissionär anzugeben, dessen Adresse allen Buchhändlern bekannt war.

Im >Börsenblatt für den Deutschen Buchhandel< annoncierte Springer seine Etablierung mit einer vom 6.4. daticrten Anzeige, die am 15., 18. und nochmals am 21.4.1842 abgedruckt wurde. Er berief sich hierbei auf sein Circular und bat um die Eröffnung eines Kontos sowie um die (unaufgeforderte) Übermittlung von Neuerscheinungen. Am 26.4. wurde Springer schließlich auch in den Börsenverein der Deutschen Buchhändler aufgenommen und war damit, noch ehe er seine Buchhandlung eröffnet hatte, Mitglied der Buchhändlergemcinschaft mit allen Rechten und Pflichten.

Springer eröffnete die Buchhandlung am Dienstag, dem 10.5. 1842, seinem 25. Geburtstag. Dies wurde acht Tage später einem »geehrten Publikum« sowie »Freunden und Bekannten« in der $>$ Vossischen Zeitung $<$ und im $>$ Berliner Intelligenz-Blatt $<$ vom 19.5. zur Kenntnis gegeben.

Das Geschäft befand sich im Hause Breite Straßc 20, Ecke Scharrnstraße, fast neben dem Rathaus. Markanteste Gebäude waren, am Anfang der Straße, der Marstall, das Ribbeckhaus sowie das zu Beginn des 18 . Jahrhunderts erbaute Haus Nr. 11, das der Schnupftabakhändler Ermeler 1824 erworben hatte. In Nr. 8 befand sich der Verlag der Vossischen Erben, in dem die >Königlich privilegierte Berlinische Zeitung< - später nur noch $>$ Vossische Zeitung< genannt - crschien. Sodann gab es eine Teehandlung (Nr.3), die Weinstube $>$ Schloßklause $<$ (Nr. 22) und Karchows Konditorei. Es war also eine s gute<, recht anspruchsvolle Geschäftsstraße für cin kaufkräftiges Publikum, in der es auch schon zwei Buchhandlungen gab: Im Hause der Vossischen Zeitung domizilierte die Trautwein'sche Buchhandlung sowie, einige Häuser weiter, die Enslin'sche Buchhandlung (Nr. 23), in der Springer gelernt hatte. Gleich um die Ecke, in der Scharrnstraße, hatte der Buchhändler Wohlgemuth scin Geschäft, in der parallel gelegenen Brüderstraße (11 bzw. 13) hatte die Buchhandlung von C.F. Amelang und auch die Nicolai'sche ihren Laden. Am Schloßplatz, also auch in der Nähe, fand man die Stuhr'sche Buchhandlung und E.S. Mittler (Unter der Stech- 


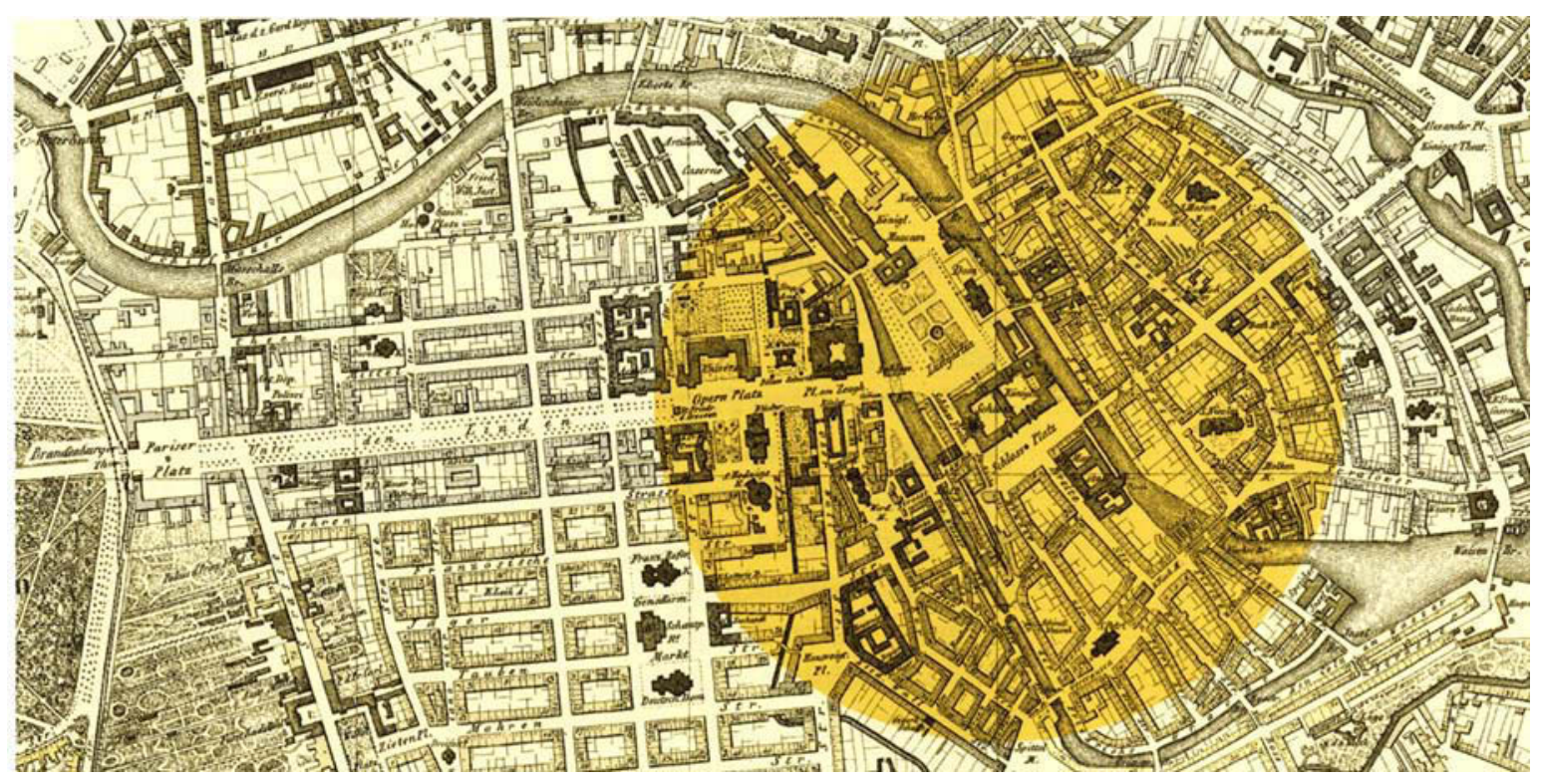

6: Berlin hatte 1842 etwa 330000

Einwohner und erstreckte sich

im wesentlichen vom Branden-

burger Tor im Westen bis

zum Alexander-Platz.

im Osten der Stadt.

Das Schloßviertel

auf der Fischerinsel

war noch das Zentrum

der politischen Macht. Die

Privatwohnung Springers lag

in der Roßstraße, die gleich hinter

dem Köllnischen Rathaus begann.

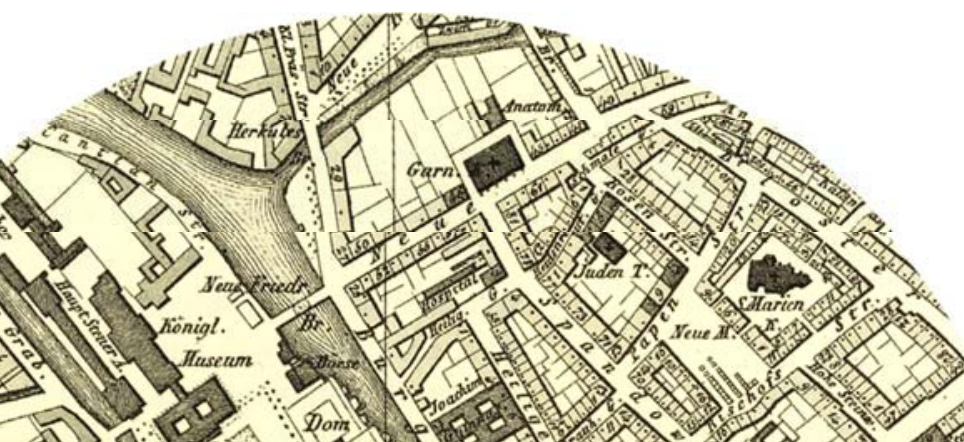


bahn). Allgemeiner Trubel herrschte in der Breiten Straße zur Adventszeit, da hier schon seit einigen Jahren der Weihnachtsmarkt seinen Platz gefunden hatte.

Das Sortiment $\mathrm{Q}$ pringer hatte sich in seiner Publikumsankündigung als $\gg$ Buchhandlung für in- und ausländische Literatur « vorgestellt und sein $\gg$ Lager von gebundenen und ungebundenen Büchern in allen Fächern und Sprachen, sowie Landkarten und Atlassen bestens« empfohlen. Er versprach, alle ihm zukommenden, schätzbaren Aufträge auf neuere und ältere Werke auf das prompteste auszuführen und nicht Vorrätiges auf das schnellste anzuschaffen. Weiterhin empfahl er sich für die Besorgung der in den gängigen Zeitungen angekündigten Bücher und versicherte, die hier angezeigten Pränumerationen und Subskriptionen zu den gleichen Bedingungen zu liefern. Schließlich rühmte er sich der Verbindung zu auswärtigen Handlungen mit großen Lagern antiquarischer Bücher.

Ankündigungen dieser Art las man zu jener Zeit nicht selten. Die rasche Ausdehnung des Unternehmens und Springers sonstige buchhändlerischen Aktivitäten lassen erkennen, daß er offenbar bald crfolgreich war, auch wenn hierfür keine dokumentarischen Belege vorliegen. Diese Spurlosigkeit ist bei Sortimentsbuchhandlungen nicht ungewöhnlich, denn ihr Wirken ist - im Gegensatz zum Verlag, bei dem es neben der verfügbaren Produktion gelegentlich auch Autorenkorrespondenz etc. überliefert ist - nur aus marginalen Hinweisen zu rekonstruieren. Man wird Marie Springer glauben, was sie bezüglich seiner Gehilfenzeit bei Jonas schreibt: daß er sehr bald beliebt gewesen sei und besonders als Verkäufer vom Publikum geschätzt wurde. So waren ihm viele Kunden von Jonas in sein eigenes Geschäft gefolgt [MS: 9].

Schon damals überzeugte Springer durch seine guten Kenntnisse in der Welt der Bücher. Auch über die öffentlichen Angelegenheiten war er immer wohl informiert. Seine gewandte Konversation, auf die auch Springers Korrespondenz dieser Jahre schließen läßt, und seine liebenswürdige Art werden ihm geholfen haben, rasch einen ansehnlichen und auch potenten Kundenkreis zu gewinnen. Hierzu gehörte auch Georg Ferdinand Oppert ${ }^{7}$. Freunde des stillen Teilhabers hatten ihn auf die Buchhandlung in der Breiten Straße aufmerksam gemacht und um seine Zuwendung gebeten. Bei einem Besuch hatte er auch den jungen Springer kennen und schätzen gelernt und ihn schließlich in sein Haus eingeladen. So wurde Springer am Zweiten Weihnachtstag 1842 mit seiner künftigen Frau Ma- 


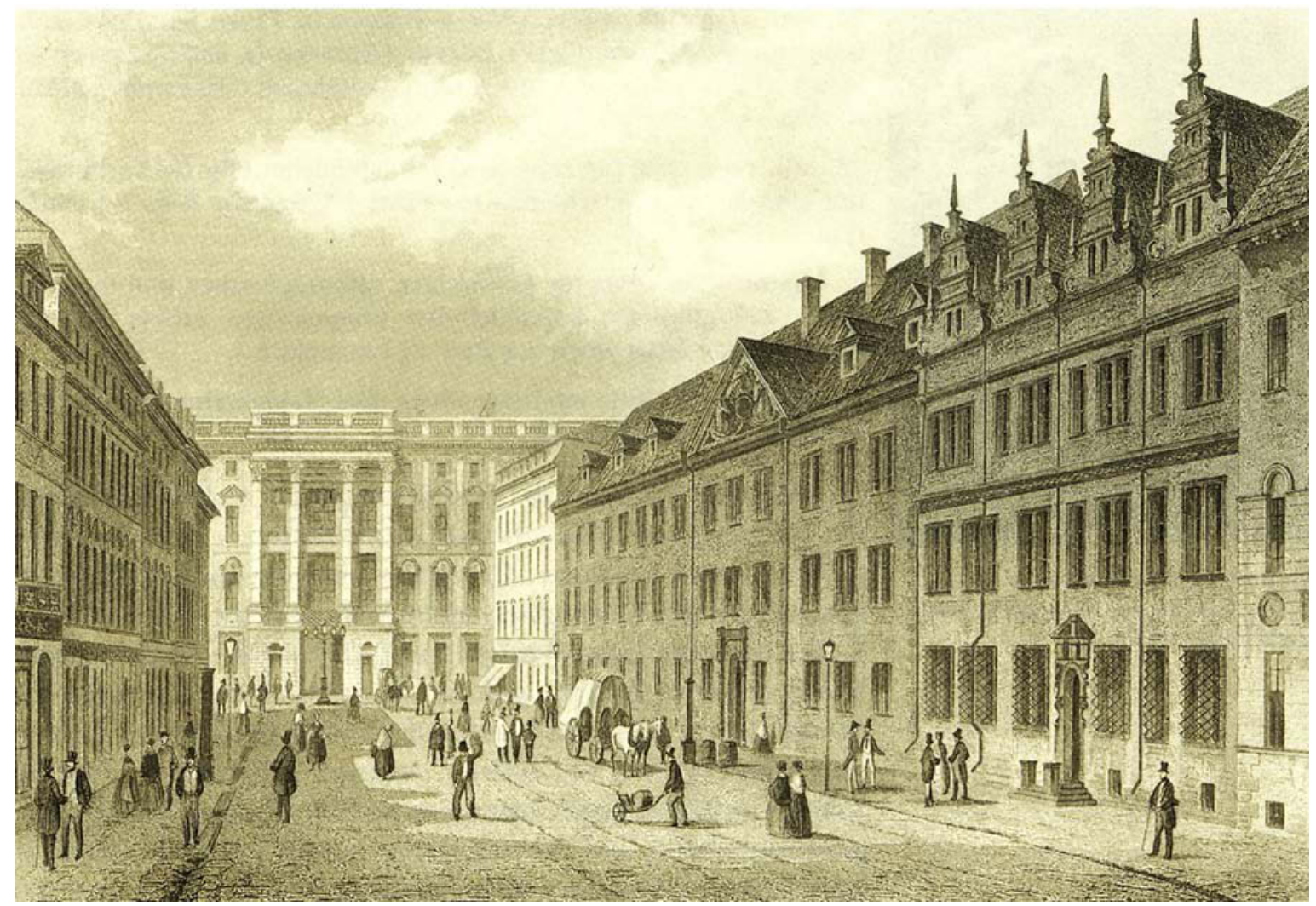

rie bekannt. Da die beiden älteren Schwestern noch unverheiratet waren, und Marie Oppert mit 16 Jahren die jüngste war, mußten sich die beiden noch eine Weile gedulden. Die Hochzeit fand dann am 3.9.1845 statt. Zu diesem Zeitpunkt war das junge Unternehmen wohl schon stabil genug, eine Familie zu ernähren.

Neuerscheinungen und Prospekte werden die Verlage Springer auf sein Circular vom 20. März hin wohl in ausreichender Stückzahl zur Verfügung gestellt haben. Dieses Material hatte sein Leipziger Kommissionär Friedrich Volckmar gesammelt und ihm fristgerecht zugestellt. Hierfür brauchte Springer - außer der Fracht - zunächst nichts zu zahlen, denn Novitäten wurden als Kommissionsgut geliefert und waren erst bei der nächsten Messe abzurechnen. Allein mit Novitäten hatte Springer freilich nur die üblichen Titel des Tages. Das Standardsortiment älterer Titel und seine Spezialitäten mußte er gezielt hinzukaufen, sofern man seinem Wunsch, ihm ein Konto einzurichten, nicht entsprochen hatte.

Bald nach der Geschäftseröffnung teilte Springer den Verlegern seine Präferenzen durch Börsenblatt-Anzeigen mit:
7: Die Breite Straße mit Blick auf den Seitenfluigel des Schlosses. Stahlstich von Barber. Springers Buchhandlung befand sich am linken Bildrand. 


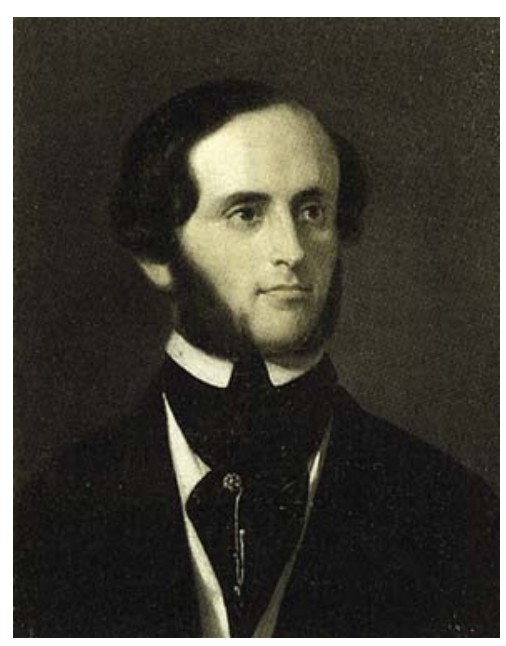

8: Julius Springer als Achtundzwanzigjähriger. Olgemälde von unbekannter Hand.
24. Mai: "Ich bitte, mir von Verzeichnissen im Preise herabgesetzter, besonders wissenschaftlicher Bücher (Romane ja nicht!) immer sogleich 20 Exemplare und von Auktionskatalogen 6 Exemplare einzusenden.«

22. Juli: »Von allen [literarischen] Taschenbüchern für 1843 erbitte ich mir sogleich nach Erscheinen zur Post: 1 Exemplar fest, 2 à condition.«

5. August: »Von allen die politischen, philosophischen und theologischen Zeitinteressen behandelnden Flugschriften erbitte ich mir sogleich nach Erscheinen zur Post 12 Exemplare."

23. August: »Ich bitte um Einsendung aller Neuigkeiten in polnischer Sprache (in 2 Exemplaren).«

So umsichtig Springer die Etablicrung auch vorbereitet hatte, die Wünsche seiner Kundschaft waren dennoch nicht so genau vorherzusehen gewesen. Er mußte also seinen Bedarf näher präzisieren. Nach der ersten Anzeige zu urteilen - sie wurde am 6. Tag nach der Geschäftseröffnung abgesandt - wird Springer kaum erwartet haben, daß in dieser Gegend >Occasionen< (heute spricht man von Sonderangeboten) derart stark gefragt sein würden. Aus der dritten Anzeige geht hervor, daß im Schloßviertel ein reges Interesse an Flugschriften politischen, philosophischen und theologischen Inhalts bestand. Schelling hatte seine Vorlesungen aufgenommen, und Kontroversen mit den Junghegelianern waren an der Tagesordnung; Herwegh besuchte Berlin, er wurde sogar vom König empfangen, aber scin Besuch endete mit einem Eklat. Springer nahm diesen Besuch zum Anlaß, ein während des Aufenthaltes gezeichnetes Porträt rasch lithographieren zu lassen und lieferte es Ende November aus. Aber dies war keineswegs der erste Anlaß, auch verlegerisch tätig zu werden.

Die Sonderinteressen des Springerschen Sortiments lagen zunächst auf den Gebieten Politik, Philosophie und Theologie. Es folgten Landwirtschaft und Forstwesen (mit steigender Tendenz im Laufe der Jahre) und Naturwissenschaften. Hinzu kamen 1845 Pädagogik und >Preußische Jurisprudenz‘, von der er scit 1847 immerhin je zehn Neuerscheinungen unaufgefordert erbat. Mit den genannten Fachgebieten sind zugleich auch einige Schwerpunkte von Springers Verlagstätigkeit in den nächsten Jahren bezeichnet.

Dic Vermutung liegt nahe, daß viele Kunden der Buchhandlung von auswärts kamen. Neben Verwaltungsbeamten, die gelegentlich in der Hauptstadt zu tun hatten und im Umfeld des Schlosses Kontakte pflegten, waren darunter sicher auch Gutsherren aus der Mark, aus Mecklenburg und den Provinzen östlich der Oder. Wie sonst wäre es zu erklären, daß die Land- 
und Forstwirtschaft in einem Berliner Sortiment diesen besonderen Rang hatte? Daß cin Teil dieser Novitäten an die >Filialen< weitergeleitet wurde (s.S. 14), darf man als sicher annehmen.

$\mathrm{S}$ pringer hatte in seiner Lehrfirma und bei Neff in Stuttgart das buchhändlerische Kommissionsgeschäft kennengelernt, und dic hier gesammelten Erfahrungen nutzte er nun in seiner Heimatstadt. Die Bedingungen dieses Buchhandelszweiges bedürfen für den Außenstehenden einer kurzen Erläuterung:

Sortimente mit einem größeren Geschäftsumfang - dies mögen 1842 etwa 500 Firmen in Deutschland gewesen sein - hatten einen Kommissionär in Leipzig. An ihn richteten sie alle Bestellungen, und er besorgte bei den jeweiligen Verlegerkommissionären dic gewünschten Bücher, um sie seinem SortimenterKommittenten zu vereinbarten Terminen als > Leipziger Ballen per Fracht zuzustellen. Insbesondere wegen der damals noch sehr hohen Transportspesen war dies ein sehr rationelles Besorgungssystem.

Bei der zunehmenden Bedeutung von Berlin als Verlagsstadt war es für norddeutsche Sortimenter aber unwirtschaftlich und zeitraubend, sich auch die Berliner Produktion über Leipzig kommen zu lassen. So nahmen manche Berliner Sortimenter Kommissionärsaufgaben für norddeutsche Kollegen wahr. Springer kannte dieses Geschäft und seinen Nutzen und veröffentlichte am 28.7.1843 eine entsprechende Anzeige im Börsenblatt. Je mehr sich das norddeutsche Eisenbahnnetz ausdehne, schreibt er, desto bedeutender werde Berlin für den norddeutschen Buchhandel. »Für viele Handlungen wird es notwendig und von großem Nutzen sein, hier einen Commissionair zu halten.«

Springers Bemühungen waren bald crfolgreich. Im November 1845, als 22 Kommissionäre 121 auswärtige Buchhandlungen in Berlin vertraten, stand Springer hinsichtlich der Zahl der Kommittenten neben sciner Lehrfirma Enslin schon an erster Stelle: jeder besorgte das Kommissionsgeschäft für 20 auswärtige Buchhandlungen. Diese Zahl besagt allerdings nichts über den Umfang des Geschäfts, denn unter den vertretenen Firmen waren auch recht unbedeutende mit einem nur minimalen Umsatz. Von Springers Kommittenten crhielten immerhin 13 wöchentlich wenigstens eine Licferung. Seinem Freund Saunier in Stettin stellte Springer allein dreimal wöchentlich eine Sendung Zu.
Kommissionsgeschäfte

(1)

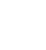


Der > Verkehr über Leipzig< lohnte sich aber nur bei einem entsprechenden Geschäftsumfang, denn zum System gchörte auch die jährliche Abrechnung auf der Leipziger Buchhändlerbörse, die für entfernter wohnende Buchhändler oft eine Reisezeit von zwei bis vier Wochen bedeutete. Eine so lange Abwesenheit konnten sich Kaufleute, die nur nebenher mit Büchern handelten, gar nicht leisten, von den Reisespesen ganz abgeschen. Sic zogen es vor, mit einem größeren Buchhändler z. B. in der Landeshauptstadt - einen Kommissionsvertrag zu schließen. Diesem Buchhändler schickten sic ihre Bestellungen, und dicser erledigte sie, zusammen mit den eigenen Aufträgen, über seinen Leipziger Kommissionär. Er versorgte sie darüber hinaus mit den Prospekten ihrer Interessengebiete und schickte ihnen auch Neuerscheinungen, für dic er bci seinen Kollegen in der Provinz cine gute Absatzchance sah.

Der Kommissionär belicferte seine Kommittenten in der Provinz mit einem reduzierten Rabatt (beim Bargeschäft statt $33 \frac{1}{3}$ nur $25 \%$ und bei Kommissionslieferung statt 25 nur $20 \%$ ) und hatte bci der Bestellung einer größeren Titelzahl einen Vorzugsrabatt als eigenen Vortcil. Springer war aber nicht nur an diesem Geschäft als solchem interessiert, sondern er bekam Einblick in die Bedürfnisse eines interessanten Marktes und konnte hieran auch seine Produktion als Verleger orientieren. So ist es nicht ganz unwahrscheinlich, daß seine späteren Erfolge als Verleger forst- und landwirtschaftlicher Bücher auch auf Kontakten zu seinen ländlichen und kleinstädtischen Kommittenten beruhten, aus deren Bedarf er Anregungen bezog. Und schlicßlich übernahm Springer auch Bücher zum Vertrieb, die diesen auswärtigen Kollegen von ihren Kunden zum Verlag angetragen worden waren.

Springer versorgte von 1843 bis 1857 als Kommissionär zeitweilig mehr als 30 Firmen in Mecklenburg, Pommern, Ost- und Westpreußen, Posen und Schlesien. Der Kontakt auch zu Firmen in Gebieten mit polnischer Bevölkerung erklärt seinen schon 1842 geäußerten Wunsch, von Neuigkeiten in polnischer Sprache unaufgefordert je zwei Exemplare zu erhalten.

In diesen 1840er Jahren gab es in Berlin Bemühungen, mit Leipzig als zentralem Kommissionsplatz für Norddeutschland zu konkurrieren, doch das Eisenbahnnetz wuchs schneller, als der Berliner Kommissionshandel an Ausdehnung gewinnen konnte. Nachdem in den 60er Jahren die Transportkosten immer mehr zurückgingen, war Leipzigs Monopol - auch im Norden Deutschlands - nicht mehr anzufechten. Wohl gelang es Berlin in den 1880 er Jahren, die Produktion Leipziger Verlage zu überflügeln, doch als Kommissionsplatz kam es nic über den 
dritten Platz - nach Stuttgart - hinaus; eine überregionale Bedeutung gewann der Berliner Kommissionshandel nicht.

Nachdem Springer sein Sortiment per 1.1.1858 in andere Hände gegeben hatte (s.S.44), vermerkte scin Nachfolger im Buchhändleradreßbuch: »Versieht 30 kleinere Buchhandlungen mit ihrem Bücherbedarf « und erbat für 13 von ihnen insgesamt je 4200 Prospekte bei Erscheinen. Doch dieses Geschäft, dic Versorgung von >Auch-Buchhändlern<, kam einige Jahre später zum Erliegen und wurde von Grossisten übernommen.

$\mathrm{S}$ pringer war ein politischer Mensch im weitesten Sinn und leidenschaftlich an allen öffentlichen Angelegenheiten interessiert. Neben der aktuellen Politik bewegten ihn die Verfassungsdiskussionen ebenso wie Streitfragen und Polemiken innerhalb der Konfessionen. Auch die Gewerbe- und Wirtschaftspolitik war für ihn als Kaufmann eine Angelegenheit des öffentlichen Interesses. So war es fast selbstverständlich, daß er sich nicht mit den Streitschriften begnügte, die ihm als Sortimenter geliefert wurden, sondern auch selbst in diesem Bereich verlegerisch tätig wurde.

Bei seiner Buchproduktion ging Springer zunächst kein gröBeres Risiko ein. Seine Mittel waren in den ersten Jahren noch sehr beschränkt, und was der Verlag beanspruchte, mußte zunächst in der Buchhandlung verdient sein. So lag der Umfang von Springers Veröffentlichungen im Durchschnitt der ersten

\section{Der Verlag}

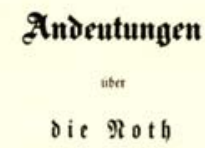

oer

\section{arbeitenten Rlaffen}

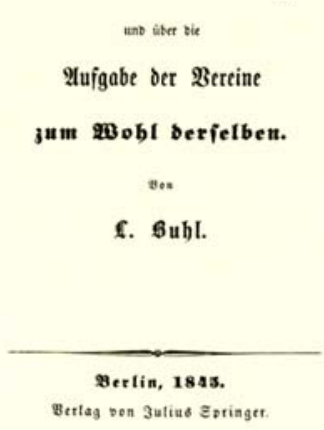

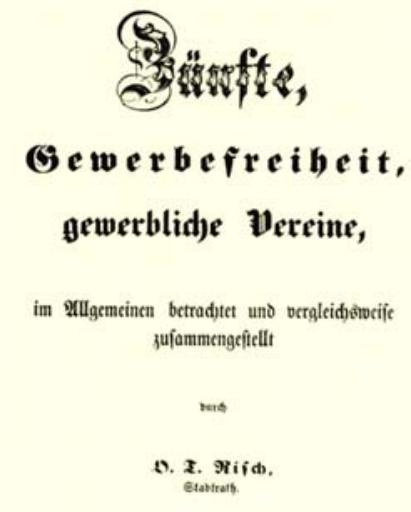

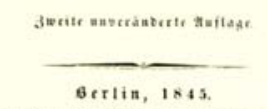

3m verlage ven 3utine aveinace.
9: Ludwig Buhl gehörte mit Bruno Bauer, Max Stirner u. a. zu einer Gruppe junghegelianischer Schriftsteller (,Die Freien ), die von Marx und Engels in ihrer Schrift, Die heilige Familier (7845) attackiert wurde. - 10: Otto Theodor Risch war in diesen Jahren mit Springer befreundet. Bei der Taufe von Ferdinand Springer (1846) war Risch Pate. 
vier Jahre noch unter jeweils 50 Seiten. Bei umfangreicheren Manuskripten war er zumcist nur zum Kommissionsverlag bereit. Das bedeutete: der Autor zahlte dic Druckkosten, und der Verleger vergütete ihm für jedes verkaufte Exemplar die Hälfte des Ladenpreises. Da er Lieferungen an andere Buchhändler in üblicher Höhe zu rabattieren hatte $-331 / 3 \%$ bei Barzahlung und $25 \%$, wenn bis zur nächsten Ostermesse zu kreditieren war-, so blieb ihm nur cin mäßiger Überschuß. Doch Springer machte seinen Namen auch auf dicsem Wege bekannt, und das war für den Neuling am Markt ein ebenso großer Gewinn.

Politisches Tn Paris hatte Springer noch die Karikaturen des Verlegers Philipon (>Caricature<, , Le Charivari<) und ihre Wirkung kennengelernt, wenngleich sic zu seiner Zeit schon verboten waren. Da nach den Zensurerleichterungen, die Friedrich Wilhelm IV. >gewährt hatte, Karikaturen in Preußen nicht mehr der Zensur unterlagen, wagte er sich im Jahr der Gründung mit sechs Blättern auf den Markt, deren erstes, die >Hermetische Grenzsperre<, er am 5. Juli, also acht Wochen nach der Firmengründung, im >Börsenblatt $<$ anzeigte. Es war dies eine recht harmlose Karikatur auf die Durchlässigkeit der innerdeutschen Grenzen und die Bestechlichkeit ihrer Bewacher. Die folgenden fünf Blätter, gezeichnet und lithographiert von R. Sabatky, sind schon agressiver: Das Blatt >Der deutsche Michel< wird 1843 sogar in einer eigenen Broschüre weitschweifig und listig verharmlosend beschricben. Bald darauf bringt Springer das Pendant heraus: >Michels Erwachen< [BRückmanN]. In anderen Karikaturblättern wird die Wiederaufnahme der Bauarbeiten am Kölner Dom aufs Korn genommen, mit denen am 4.9. 1842 begonnen worden war. Das letzte Blatt der Folge, >Eintritt der Zensur in Deutschland $<$ ging dann schon fast über die Grenzen des gerade noch Geduldeten hinaus.

Schon im Februar 1843 wurden >Bilder ‘, also auch Karikaturen, wieder der Zensur unterworfen, und so verzichtete Springer auf die Herausgabe weiterer Blätter. Ein bedeutendes Geschäft können sie kaum gewesen sein, doch man darf annchmen, daß Springer mit diesen Karikaturen schon im ersten Jahr seiner Selbständigkeit liberal gesinnte Berliner für sich zu interessieren vermochte und damit auch manchen Kunden und Autor gewonnen hatte.

Am 28.7. 1843 kündigte Springer im >Börsenblatt< scine erste Zeitschrift an: >Der Staat. Monatsschrift für öffentliches Leben $<$. Die Auflage sollte 2000 Exemplare betragen; Redakteur 


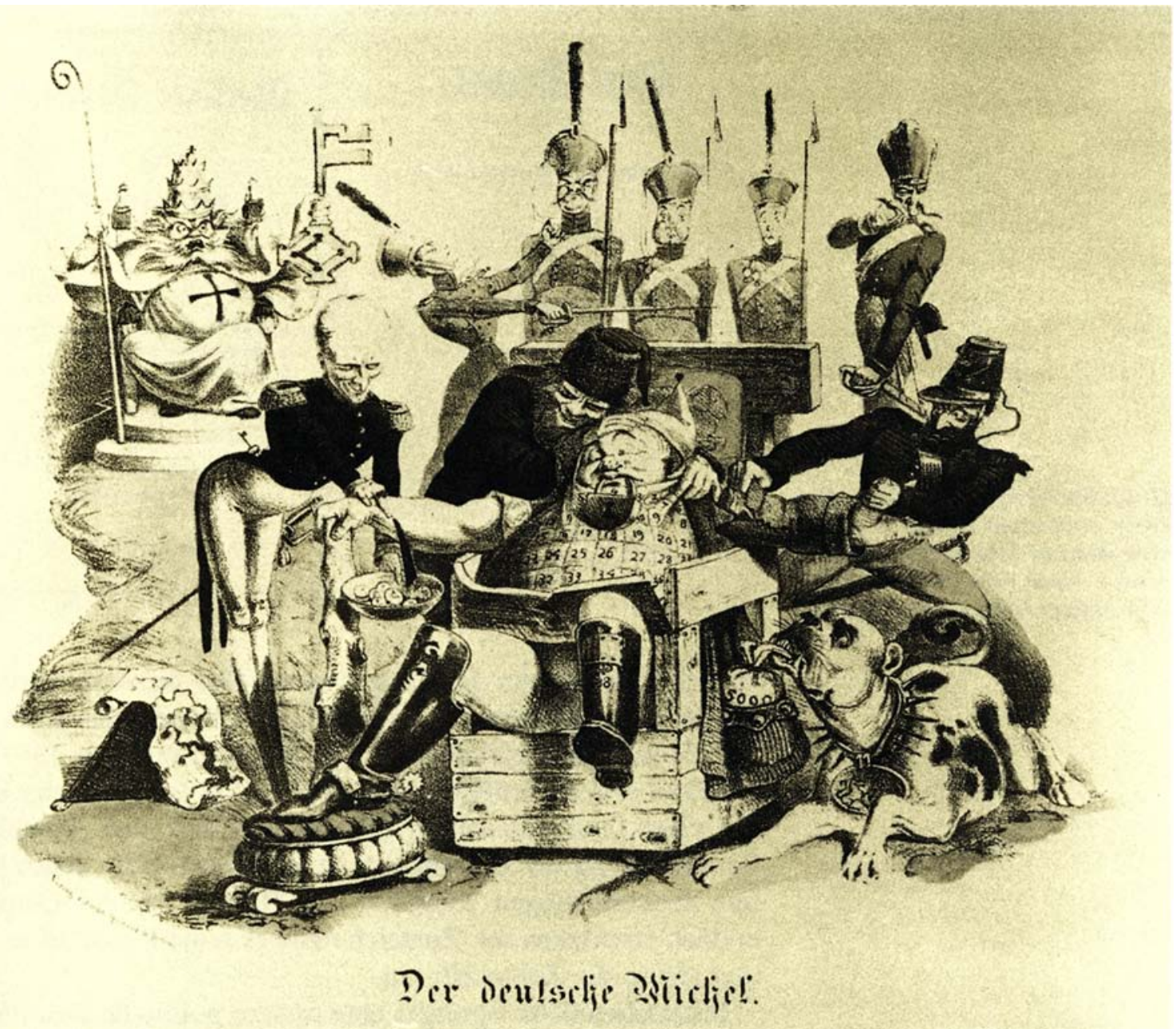

und Hauptautor war der damals 28jährige Schriftsteller August Theodor Woeniger. Die Beiträge des ersten Heftes galten der Öffentlichkeit des Gerichtsverfahrens und der Zensur, also recht brisanten Themen zu jener Zeit. Außerdem wurden »wichtige kommerzielle Verhältnisse des Zollvereins« und die Verhältnisse der evangelischen Kirche in Mecklenburg behandelt, denen später auch einige Einzelveröffentlichungen Springers galten. Auf die Gunst eines breiten Publikums spekulierte die Zeitschrift nicht. Die Absichten des Herausgebers und seines Verlegers, »die Lethargie für öffentliche Interessen... in Beweglichkeit umzugestalten «, wurden vom Publikum nur mäBig honoriert, aber die Zensur wurde mißtrauisch. Schon das erste Heft, das Springer für Oktober 1843 angekündigt hatte, konnte erst im November erscheinen: der Zensor hatte zwei längere Beiträge gestrichen. Im November mußte Springer dann im >Börsenblatt < mitteilen, daß auch das zweite Heft
11: $>$ Der deutsche Michel war Springers verbreitetste Karikatur. In einem berstenden Kinderstuhl sitzt der beleibte deutsche Michel und schläft. Er hat ein Maulschloß und bekommt vom Zaren ein Lätzchen umgehängt, dessen numerierten Felder die 38 souveränen deutschen Staaten versinnbildlichen. Kanzler Metternich läßt ihn zur Ader, wobei das Blut zu Geld wird. Der Franzose versucht Michel den linken Arm (= die linksrheinischen Gebiete) abzutrennen, die englische Bulldogge vergreift sich an Michels Geld; oben links droht der Papst mit dem Schlüssel Petri. Im Hintergrund exerziert unbeteiligt das Bundesheer /nach Brückmann]. 
12, 13: Springers erste Zeitschriften waren politischen Inhalts. Sie bereiteten ihm nur Scherereien mit dem Zensor. Nach dem Erscheinen jeweils einiger Hefte stellte er sie ein.

\section{Der Etant.}

Wonatdfdrift für öffentlides $\mathrm{geb}$ cu.

sobigit

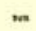

2tuguft Theobor aboeniger.
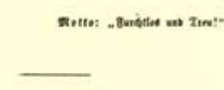

3 meiter 3abrgang.

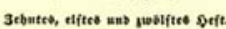

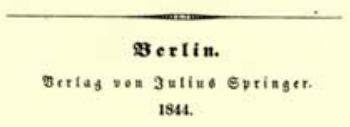

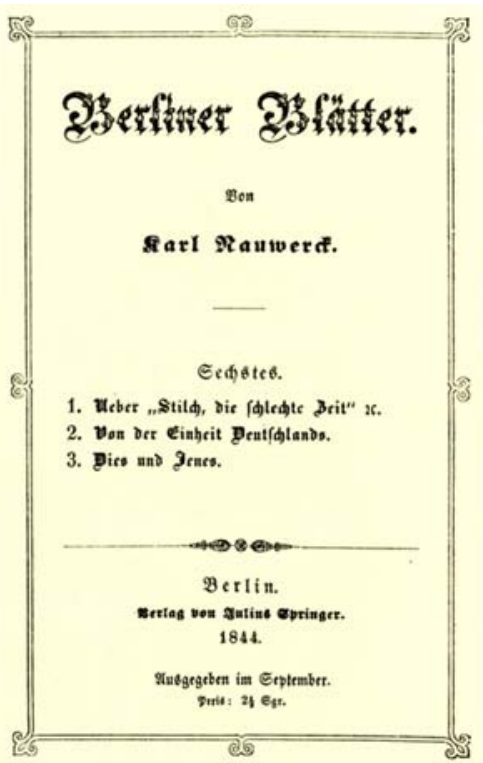

»durch Maßnahmen der Censur unmöglich gemacht worden « sei. Auch wegen der weiteren Hefte gab es ständig Querelen mit der Zensur. Die letzten beiden Hefte des Jahrgangs 1843 erschienen erst im Frühjahr 1844, und der zweite Jahrgang kam mit einer Dreifachnummer erst im Mai 1845 zum Abschluß. Springer zeigte im >Börsenblatt < an, daß dieses Heft, »nach harten, sechsmonatigen Kämpfen und Ringen mit der Censur « endlich erschienen sei. Zugleich teilte er seine Resignation mit und stellte die Zeitschrift ein.

Inzwischen hatte Springer eine andere politische Zeitschrift gegründet, die von Karl Nauwerck herausgegebenen $>$ Berliner Blätter<, die es vom März bis September 1844 auf sechs Hefte mit insgesamt 156 Seiten brachten. Nauwerck, ein Junghegelianer, war genötigt worden, seine Vorlesungen an der Berliner Universität einzustellen und betätigte sich nun als politischer Journalist. Obwohl das erste Heft bald nachgedruckt werden mußte, hatte das Blatt keinen nachhaltigen Erfolg. Angesichts der verschärften Zensur war eine Fortsetzung sinnlos geworden. Beide Zeitschriften waren so kurzlebig, daß sie in Darstellungen der politischen Journale des Vormärz bisher unbeachtet geblieben sind.

Mehr Erfolg hatte Springer mit seinen Büchern zu politischen und wirtschaftlichen Fragen der Zeit, auch wenn sic inhaltlich kaum weniger brisant waren als die Zeitschriften. Otto Theodor Risch, später mit Springer Mitglied des Berliner Stadtrats, veröffentlichte zwei Broschüren über >Das preuBische Seehand- 
Bahn, Adolph: Berlin's VolksKampf. Eine übersichtliche Darstellung der Märzereignisse und treue Schilderung des Kampfes in der Nacht vom 18. zum 19. [März] 1848. $51 \mathrm{~S}$.

Benda, Daniel Alexander: Katechismus für wahlberechtigte Bürger Preußens, oder Geist und Bedeutung der Städte-Ordnung vom 19. November 1808 . 1843. $32 \mathrm{~S}$.

Berliner Blätter. Hrsg. von Karl Nauwerck. 6 Hefte. 1844

Bluhm, Julius: Kurzgefaßte Darstellung des gegenwärtigen Standpunktes des Kriegsmarinewesens in Europa und Amerika. Zur Würdigung der deutschen Marinefrage und Flottenentwürfe. 1848 . II, $32 \mathrm{~S}$.

Böckh, August: Rede zur Feier des Allerhöchsten Geburtsfestes Seiner Majestät des Königs Friedrich Wilhelm des Vierten in der Friedrich-Wilhelms-Universität zu Berlin am 15. October 1842 gehalten. Aus dem Lateinischen und mit Vorw. von Ludwig Driesen. 1842. 17 S. $4^{\circ}$

-: Rede zur Feier des Allerhöchsten Geburtsfestes Seiner Majestät des Königs Friedrich Wilhelm des Vierten in der Friedrich-Wilhelms-Universität zu Berlin am 15. October 1843 gehalten. 1844. $40 \mathrm{~S} .8^{\circ}$

Buhl, Ludwig: Andeutungen über die Noth der arbeitenden Klassen und über die Aufgabe der Vereine zum Wohl derselben. $1845.36 \mathrm{~S}$.

Der deutsche Michel. Politische Karikatur. Lithographie von R. Sabatky. 1842.

Eichholz, Ehrenreich: Was haben wir durch die Revolution verloren? Was haben wir durch die Revolution gewonnen? Eine Zuschrift an das preußische Volk. 1848. IV, $12 \mathrm{~S}$. Tonplatte!

- Leopold Volkmar: Der Entwurf des preußischen Verfassungs-Gesetzes kritisch beleuchtet. $1848.31 \mathrm{~S}$.

[Der Eintritt der Censur in Deutschland.] Politische Karikatur. Lithographie von R. Sabatky. 1842.

Entwurf eines Gesetzes über das Verfahren in Untersuchungssachen mit Geschwornen-Gerichten. Nebst den Motiven. Der Preußischen National-Versammlung eingereicht durch die Abgeordneten: v. Kirchmann, Kämpf, Schulze [-Delitzsch] und 68 andern. 1848. II, $36 \mathrm{~S}$.

Guttek, J.: Frankreichs dritte Revolution. Eine übersichtliche Darstellung der Februar-Ereignisse in Frankreich nebst einer geschichtlichen Einleitung. 1848. $68 \mathrm{~S}$.

Gutzkow, Karl: Ansprache an das deutsche Volk. 1848. 16 S.

Hermetische Grenzsperre. Politische Karikatur. Lithographie.

Holtzendorff-Vietmannsdorf, Franz von: Vortrag über die politische Stellung der Stände, ihr Verhältniß zu den Kreistags-Versammlungen und dieser zu den Provinzial-Landtagen, gehalten auf dem Kreistage zu Templin am 8. Juli 1843. (1. Auflage 1844 beschlagnahmt) 2. Aufl. 1844. $24 \mathrm{~S}$.

Kellermann, Ludwig: Urtheil in Sachen der Krone wider die National-Versammlung und der $\mathrm{Na}-$ tional-Versammlung wider die Krone. Vom Standpunkte des Gesetzes und der politischen Grundideen des Constitutionalismus. $1848.15 \mathrm{~S}$.
[Michel's Erhebung.] Politische Karikatur. Gegenstiick zum ,Deutschen Michel . Lithographie von R. Sabatky. 1842.

Nees von Esenbeck, Christian Gottfried Daniel: Die demokratische Monarchie. Ein GesetzVorschlag, der National-Versammlung zu Berlin vorgelegt den 1. Juli 1848. 1848. 26 S.

Saint-René-Taillandier, René Gaspard Ernest: Die politische Literatur in Deutschland. Aus dem Französischen von Moritz Haase. 1844. $70 \mathrm{~S}$.

Der Staat. Monatsschrift für öffentliches Leben. Hrsg. von August Theodor Woeniger. 5 Hefte. 1843/44.

Uhlich, Leberecht: Worte und Thaten in Berlin seit dem 9. November 1848. 1. Kor. 13,1. Nebeneinandergestellt von einem Mitgliede der Nationalversammlung. $1848.8 \mathrm{~S}$.

Volkmar, Leopold: Die Selbständigkeit der unteren Instanzen, gefährdet durch das Königliche Ober-Tribunal. 1843. 32 S.

Waller, E.: Welche Motive können dem neuen Judengesetze zu Grunde liegen? 1842. 19 S.

Werther, Carl Ludwig: Umwandlung der Schlacht- und Mahlsteuer in eine Einkommenssteuer ist ein Beförderungsmittel zur Revolution. 1847. 22 S.

Wolff, C. M.: Über Volkssouveränität und die Grundlagen der constitutionellen Staatsverfassung, mit besonderer Rücksicht auf Preußen. 1848. 58 S.

Die Wünsche der Presse an den ersten Vereinigten Preußischen Landtag. 1847. $32 \mathrm{~S}$. 
lungsinstitut und dessen Eingriffe in die bürgerlichen Gewerbe< sowie eine andere über Zünfte, Gewerbefreiheit und gewerbliche Vereine. Beide Schriften richteten sich ziemlich aggressiv gegen die Wirtschaftslenkung des Staates. (Die >Königliche Seehandlung war die staatseigene Handelsbank.) So balancierte Springer an der Grenze des gerade noch Geduldeten.

Daß Springer bereits 1842 und 1843 die Reden >zur Feier des Allerhöchsten Geburtstagsfestes Seiner Majestät des Königs< publiziert hatte, sollte nicht als Reverenz vor dem Thron mißverstanden werden. Laudator war, wie schon im Jahr zuvor und auch im folgenden Jahre, der Gräzist August Böckh, seit 1811 Professor der Beredsamkeit und der klassischen Literatur an der Berliner Universität, derzeit Rektor, Mitglied zahlreicher Akademien und später auch Ehrenbürger der Stadt Berlin. Wohl ließ er es nicht an Elogen und den üblichen Untertanenfloskeln mangeln, doch an seiner politischen Gesinnung ließ Böckh keinen Zweifel: Als freiheitlicher Bürger erweise sich, wer »die geheimen Gebrechen des Staates erst enthüllt ... unkluge oder schlechte Maßregeln bekämpft... oder sie auch, wenn es Not tut, rügt mit Ernst und Strenge«. Erst »wenn die Monarchie zugleich ein Bürgerstaat ist «, gäbe es »in diesem Staate Freiheit «, und $» j e$ freier die Monarchie konstituiert ist, desto inniger wird gewöhnlich der Fürst geliebt «. Und es fehlte auch nicht an der Warnung, die Freiheit der Wissenschaft einzuengen, wozu gerade des Königs Minister Eichhorn neigte. »Man kann die Wissenschaft nicht begünstigen, wenn man sie so geleitet wünscht, daß sie zur Befestigung der Herrschaft oder zur Verteidigung gewisser Meinungen diene. Die Wissenschaft kann nur gedeihen, wenn sie frei ist.«

Böckh konnte so offene Worte noch im Jahr 1842 aussprechen, zumal auf Latein, dem kaum jeder Zuhörer hatte folgen können. Für den Verleger war die Veröffentlichung der deutschen Übersetzung aber nicht ungefährlich, zumal der Übersetzer Ludwig Driesen manche Formulierung wohl noch verschärft haben wird. Der Argwohn der Zensurbehörde war ihm jedenfalls sicher, zumal er sich durch die Karikatur >Der Eintritt der Censur in Deutschland (1842) schon hinreichend verdächtig gemacht hatte.

Erste Kontakte zu $\mathbf{V}$ eben Büchern zu Problemen des Tages haben zwei große Jeremias Gotthelf 1 literarische Unternehmungen das verlegerische Interesse Springers in dieser Zeit beansprucht und auch die wirtschaftliche Entwicklung des Unternehmens beeinflußt: Seine erfolgreichen Bemühungen um den Verlag der Bücher von Jeremias 
Gotthelf - mit bürgerlichem Namen Albert Bitzius und von Beruf Pfarrer in Lützelflüh im Emmental - und eine gemeinsam mit dem Berliner Buchhändler Simion gegründete , Verlagshandlung des allgemeinen deutschen Volksschriften-Vereins< [KNOCHE (1)].

Jeremias Gotthelf ist unter den Springer-Autoren dieser Jahre zweifellos der bedeutendste, und ohne ihn wäre die Schöne Literatur im Verlagsprogramm fast in einer Fußnote abzuhandeln. ${ }^{8}$ Eine Darstellung dieser literarischen Phase ist in ciner Geschichte des Springer-Verlags aber nicht nur wegen der Bedeutung des Autors gerechtfertigt; über sie gibt es eine kaum mehr überschaubare Literatur, darunter allein drei Arbeiten über die Verlegerbeziehungen Gotthelfs [AndermatT; HöVEL (2); JukER]. Dieser Kontakt, der durch reichlich 100 Briefe dokumentiert ist, zeigt, wie geschickt Springer schon zu Beginn seiner Verlegerlaufbahn bei der Gewinnung von Autoren war. Für die frühe Geschichte des Verlags ist diese Korrespondenz auch deshalb so wichtig, weil aus den Jahren bis 1857 nur wenige Aufzeichnungen von Springers Hand und keine weiteren Korrespondenzen vorliegen.

Springer hatte den Kontakt zu Gotthelf schon im August 1843 aufgenommen, als in seinem Verlag erst einige kleinere Schriften erschienen waren, unter denen sich Literarisches kaum ausmachen läßt. Da er die zeitgenössische Jugendschriftenproduktion als unbefriedigend empfand, unterbreitete er Gotthelf den Vorschlag, ein Jugendbuch zu schreiben, »denn nur wenigen ist diese klare, natürliche, ja ich möchte sagen, wohltuende Darstellungs- und Schreibweise gegeben, wie sie in Ihren Werken sich gibt und wie solche gerade in einer Jugendschrift am schönsten wirkt...« (28.8.1843). Es spricht alles dafür, daß Springer schon damals beabsichtigte, Gotthelfs gesamte Produktion für seinen Verlag zu gewinnen. Möglicherweise hatte er ein Jugendbuchprogramm nur vorgeschoben, denn weitere Planungen sind aus dieser Zeit nicht bekannt.

Gotthelf, der mit seinen bisherigen Verlegern sehr unzufrieden war - immerhin waren es schon derer fünf in fünf Jahren, und zu weiteren hatte er Kontakt gesucht - , hatte bisher nur recht spröde, rein geschäftliche Briefe von seinen Verlagspartnern erhalten. Springer aber umwarb ihn mit aller ihm zu Gebote stehenden Beredsamkeit, und er sparte auch nicht mit Schmeicheleien. Schon beim >Bauern-Spiegel<, den er bereits im Jahr des Erscheinens (1837) in Zürich gelesen habe, hätte er sich zu der $\gg$ so unübertrefflichen Darstellungsweise hingezogen« gefühlt und auch »spätere Schriften mit dem wahrsten Interesse und der größten Befriedigung . . . aufgenommen «. Seit

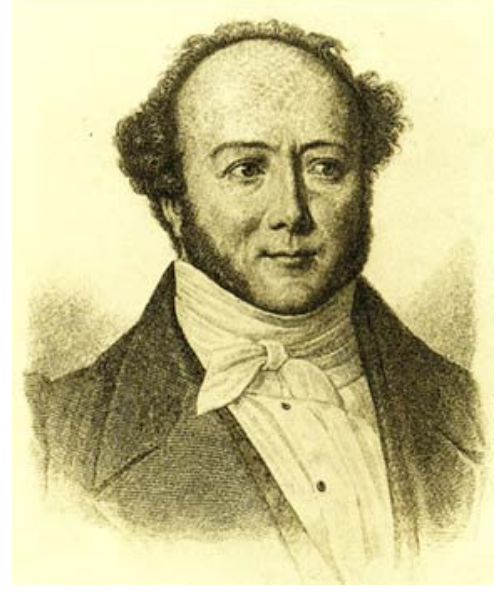

14: Jeremias Gotthelf. Stich von Carl von Gonzenbach für die > Gesammelten Schriften. Gezeichnet nach dem bekannten Porträt von Johann Friedrich Dietler, Bern 1844. 
15: Gothelfs einziges. Jugendbuch fand nur wenig Zuspruch. Es war nach Springers Urteil das am wenigsten gelungene Werk des Dichters. - Die Nennung von Höhr als Mitverleger sollte das Buch vor Nachdrucken in der Schweiz schïtzen. (Vgl. Abb. 25.)

Der

\section{Suabe Des Tell.}

Einc (joçdid)te für oie ฐัugeno

Jeremias Gotthelf.

Berlin, 1846.

Berlag vou 3utius Springer.

Brette. Etrate stit. 30.

Bürid, bei G. Goechr. seiner Etablierung sei er bestrebt, »den Schriften aus Ihrer Feder die möglichste Verbreitung gerade in unseren Landen des Nordens...« zu verschaffen, und er sei »glücklich, sagen zu können: nicht ohne Erfolg « (28.8.1843). Solche Worte hören Dichter gern, und so mag Gotthelf sich bewogen gefühlt haben, das Angebot des Berliner Verlegers zu überdenken, der sich auch persönlich so lebhaft von seinen Werken angesprochen zeigte.

Schon in seinem nächsten Brief (16.11.1843) macht Springer den umworbenen Autor auf einen anderen Vorteil aufmerksam, den der Kontakt zu einem deutschen Verlag für ihn habe: $» S$ chweizerischer Verlag genießt in Deutschland durchaus keines Schutzes. Bei einiger weiterer Hinweisung und Hervorhebung Ihres gefeierten Talentes wird die böse Spekulation des Nachdrucks diese bald auszubeuten wissen, und wird vom Gesetz ferner nicht gehindert. Dieser Umstand dürfte auch Ihrerseits wohl zu beachten sein. "Einige Zeit später (26.1.1846) kam Springer auch das umgekehrte Risiko zum Bewußtsein: Um den Nachdruck eines in Preußen gedruckten Werkes von Gotthelf in der Schweiz zu verhindern, werde er versuchen, »den Titel des Buches jedesmal in Zürich mit Höhrs Firma und auf der Rückseite der Firma einer Zürcher Buchdruckerei drucken zu lassen, wodurch ich wenigstens ein ostensibles Recht in der Schweiz erlange «. Soweit trieb Springer die Fiktion eines separaten Auflagendrucks in der Schweiz freilich nicht, aber er setzte recht häufig auf den Umschlag außer seiner eigenen Firma noch die des früheren Prinzipals Höhr und die der Buchhandlung Huber. Höhr ist schon auf der ersten Gotthelf-Veröffentlichung Springers als Mitverleger genannt.

>Der Knabe des Tell<, Gotthelfs erstes und cinziges Jugendbuch, erschien im Herbst 1845, trug jedoch, wie fast alle nach der Herbstmesse veröffentlichten Bücher, die Jahreszahl des Folgejahres auf dem Titelblatt. Es war, wie Springer später an Gotthelf schrieb, »das am wenigsten gelungene «Buch des Dichters. Das Echo der Presse war schwach, und der Verkauf lag weit unter den ursprünglichen Erwartungen. Eine zweite, 1852 gedruckte Auflage verkaufte Springer zum halben Preis. Sie war noch 1911 lieferbar.

Ehe noch > Der Knabe des Tell < erschienen war, hatte Springer schon weitere Fäden gesponnen, und es ist nicht mehr zu verkennen, daß er entschlossen war, der Verleger aller künftigen Buicher Gotthelfs zu werden. Aus einem Brief des Dichters, der ihn noch zu Weihnachten 1845 erreicht hatte - von den Briefen Gotthelfs an Springer sind nur fünf überliefert -, mag dieser die Hoffnung geschöpft haben, daß wohl auch Gotthelf eine dau- 
erhafte Verlagsverbindung suchte und sich nicht weiter verzetteln wollte. Die Bedenken Gotthelfs, Springer weitere Zusagen zu machen, münzte der Verleger sogleich zu seinen Gunsten um, indem er ihm am 1.1.1846 schrieb: »Sie haben recht; es ist für einen Autor nicht gut, bald diesen, bald jenen Verleger zu haben, abgesehen von den kleinen Unbequemlichkeiten und Inkonvenienzen, die ein Changieren derart mit sich bringt, legt der Buchhandel namentlich umgekehrt auf die Produkte der häufig auftretenden Autoren, wenn solche einer Firma angehören, einen größeren Wert, und auch das Publikum fängt an sich zu gewöhnen, die Firma mit zum Buche zu zählen.«

In seinem nächsten Brief (26.1.1846) wird Springer noch konkreter und schlägt seinem neuen Autor vor, zunächst ihm alle Manuskripte anzubieten, die bis 1852 fertig würden und hierfür eine Entscheidungsfrist von vier Wochen zu akzeptieren. Er bot Gotthelf ein Bogenhonorar von 12 Talern preußisch Courant, wobei er eine Auflage von jeweils 2500 Exemplaren zugrundegelegt hatte. Für die Bearbeitung früherer, schon gedruckter Ausgaben sollte das Honorar nur $11 \frac{1}{3}$ Taler betragen. Als Gotthelf Einwendungen wegen der Option erhob, schlug Springer vor, »wenn Ihnen erwiesenermaßen von einer anderen Handlung ein höheres als das zwischen uns stipulierte Honorar offeriert werden sollte, ich entweder ein gleiches zahlen oder Ihnen die Verlaggabe freistellen muß«. Das war immerhin ein faires Angebot. Auch wenn sich Gotthelf nicht festlegte, so hatte Springer mit seinem Vorschlag doch eine gute Voraussetzung für die künftige Verbindung geschaffen. Daß gleichwohl wegen der Höhe des Honorars immer wieder gehandelt wurde, wobei Gotthelf gewiß nicht den kürzeren zog, steht auf einem anderen Blatt. Abgesehen von drei kleineren Arbeiten, blieb Springer von nun an der einzige Verleger Gotthelfs.

Im Juli 1846 erschien dann >Uli, der Knecht<, eine hochdeutsche Fassung von >Wie Uli der Knecht glücklich wird<, zu der Springer den Dichter überredet hatte. Die Umschrift war eine für Gotthelf plagenreiche Arbeit, zu der Philologen stets ein kritisches Verhältnis gehabt haben. Man sollte aber Springer wegen dieses Vorschlags nicht tadeln. Immerhin waren ihm die Schweizer Dialekte aus seiner Zürcher Zeit recht vertraut, und er wußte von seiner Sortimentskundschaft, daß die starke Dialektfärbung für manchen ein Kaufhindernis war. Schon Sauerländer in Aarau, dem Gotthelf im Herbst 1837 >Die Leiden und Freuden eines Schulmeisters $<$ angeboten hatte, nahm Anstoß an den »vielen Redensarten im Berner Dialekt, die schon in der östlichen Schweiz nicht mehr verstanden würden, geschweige denn in Deutschland « (3.2.1838). Immerhin haben Springers
16: Uli, der Knecht erschien »zugleich mit unserem ältesten Sohn Ferdinand (21.7.1846), der noch lange Jahre im Geschäf >der kleine Uli< genannt wurde $[M S: 23]$. Ihn auch Uli taufen zu lassen, hatte sich Marie Springer nicht entschlieBen können. Ferdinand wurde der Name ihres Vaters gegeben.

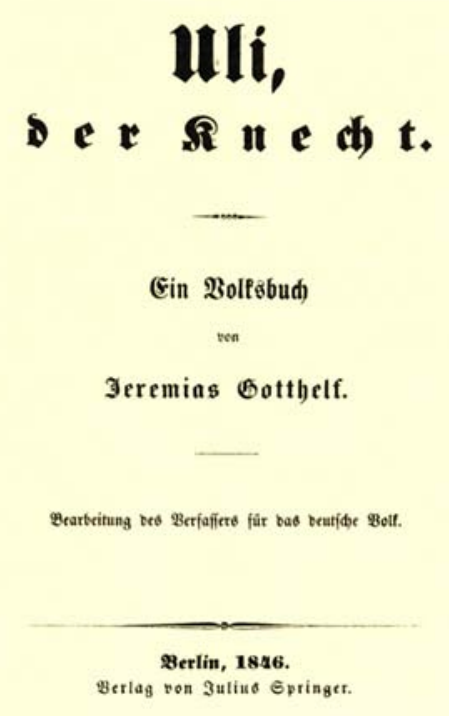

erlag ven 3uliuo Epringer. 
häufig wiederholte Hinweise, mit der Verwendung von Dialektausdrücken sparsam zu sein, bewirkt, daß Gotthelfs Dichtungen, »die seit den Springer-Kontakten entstanden waren, deutlich weniger Mundart aufweisen als die früheren « [ANDERMATT: 54].

Mit dem Verkauf ist Springer sehr zufrieden: »Der Uli fängt an, sich aller Orten bahnzubrechen und Anklang zu finden.« Springer verbindet diese Erfolgsmeldung gleich mit cinem dezenten Hinweis auf seine eigene Rührigkeit: »Die Art und Weise, wie ich für dessen Verbreitung wirkte, wird allen Ihren Schriften zustatten kommen, und schon jetzt darf ich sagen, daß selbst Ihre früheren, älteren Werke, Nachfrage und Publikum gewinnen.«Und schließlich meldet Springer sogleich sein Interesse an einer Fortsetzung des Uli an (14.9.1846).

Der Volksschriften-Verein $\mathbf{Q}$ eit den frühen 1840er Jahren wurden von Angehörigen des liberalen Bürgertums Volksschriften-Vereine gegründet, die ihre Leser in den unteren städtischen Schichten, beim Handwerker- und Bauernstand suchten. Sie wollten dem >einfachen Volk < Lesestoffe zur Verfügung stellen und damit einen Beitrag leisten zur Herstellung bzw. Sicherung des sozialen Friedens in dieser Zeit gesellschaftlicher Unruhe. Mit finanzieller Unterstützung aus dem Bürgertum und durch direkten Vertrieb sollten die Bücher zu einem erschwinglichen Preis angeboten werden.

Die Ideale dieser Bewegung dürften den volkspädagogischen Ambitionen Springers nicht ferngelegen haben, doch die Vertriebsform, die auf den Buchhändler als Mittler verzichtete und das Verlagsgeschäft in die Hände von Unprofessionellen gab, wird er mit Unbehagen verfolgt haben. Und als der Zwickauer > Verein zur Verbreitung guter und wohlfeiler Volksschriften< 1846/47 ein Buch von Jeremias Gotthelf in Erstausgabe herausgab ( $>$ Jacobs, des Handwerksgesellen, Wanderungen durch die Schweiz $<$, war Springer verschnupft, obwohl die Anregung zu diesem Werk von den Zwickauern ausgegangen war. Auch er, Springer, halte sehr viel von Volksschriften, schrieb er dem Dichter am 1.3.1846, »und es kann wohl sein, daß ich mit einem mir befreundeten Verleger eine ganze Sammlung einzelner guter Volksschriften kriege. Zu solcher wünschten wir nun eben einiges gleich von Ihnen. S Schon am 13. März ergänzte er, Auerbach, Spindler, Schubert und »andere gefeierte Männer« hätten ihre Mitwirkung zugesagt.

Die Idee zur Gründung des Volksschriften-Vereins könnten Springer und sein Partner Simion unabhängig voneinander 
gehabt haben. Simion verfügte über Erfahrungen im Verlag von Volksschriftstellern und publizierte 1843-1847 den Kalender $>$ Hausfreund in Hütten und Palästen $<$. Springer hingegen hatte den Kontakt zu Gotthelf, der für ein solches Unternehmen besonders attraktiv war. Daß er in einer Situation, in der er sich des Autors noch keineswegs sicher wähnen durfte, schon ein anderes Unternehmen mit ihm plante, könnte auch wirtschaftliche Gründe gehabt haben, denn Gotthelf hatte schon damals recht hohe Honoraransprüche, und die Absatzchancen für seine Bücher waren für Deutschland noch keineswegs sicher.

In der Unternehmensform, die Springer und Simion für den Verlag des Volksschriften-Vereins wählten, könnte eine Bestätigung dieser Skrupel liegen. Im Gegensatz zu den bestehenden

Rac ben eingegangenen 2 eftellungen wurbe verfandr:

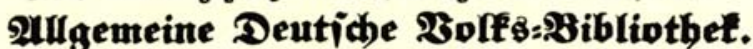 \\ Crfer sabrgang. \\ Erfter $\boldsymbol{B}$ and. \\ Inbalt: \\ Rätbi bie Eroßimutter, \\ oder ber wabre Beg ourd jede Rotb. \\ Bon Jeremias Botthelf. \\ Ir
}

Sach großen und mùbevollen $\mathfrak{B}$ orbereitungen und nadbem es une gelungen, unferm unternebmen bie Empfeblungen bober borden und Sònner jujuwenden, find wir nun jur Beriendung bes obigen erften Ibeiles unferer $\mathfrak{B}$ oltoss:Bibliotbet getommen, und baben bemfelben ùberall eine Qunjabt ausfubrticher Profpecte beis getegt.

Die folgenden bànde bes er ften Jakrganges 1847, welcer aus orei Bübern befteben und welde fanel auf einander folgen werben, entbatten:

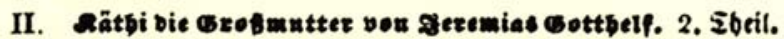

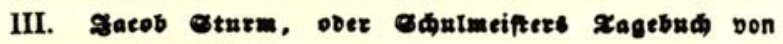
Entay sieris.

Preis ocs Jabrgangs 1847 aus 3 Bánden beftebend 20 Egr. gair empfeblen das unternebmen den gefammien Bubbandel jur beften Berwendung, und bitten diejenigen geebrten bandlun: gen, welche ben erften Sbeil nibt erbielsen, gefäligit ju verlangen, wic aud Profpecte und Subfcriptionstiften in beliebiger $\varkappa_{n_{j}} a b l$ ju Dienften fteben.

Dertin, im Dorober 1847.

Die వexlagsbandlung des allgemein beut:

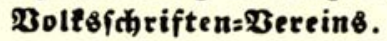

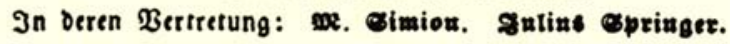

17: Die , Verlagshandlung des allgemeinen deutschen VolksschriftenVereins nahm ihre Tätigkeit in einer wirtschaftlich kritischen Zeit auf. Der Erfolg blieb ihr auch aus anderen Gründen versagt. 


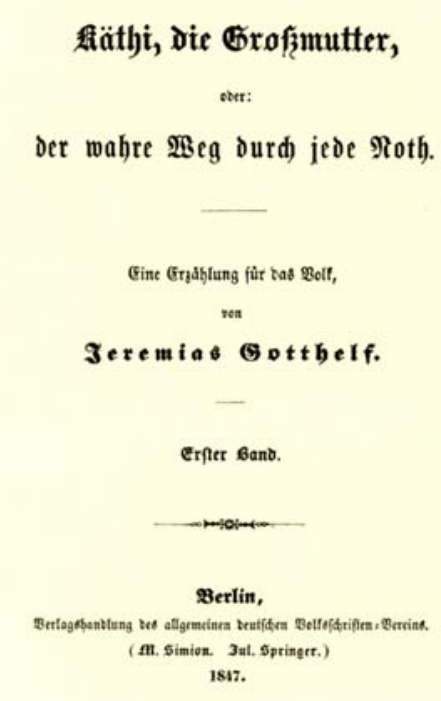

18: Das erste Buch des Volhischriften-Vereins war auch scin erfolgreichstes.
Volksschriften-Vereinen wollte man das Sortiment nicht nur in den Vertrieb einschalten, sondern auch als Verlagspartner beteiligen. Eine derartige Kooperation mit dem Charakter einer Aktiengesellschaft war nicht ganz neu im Buchhandel. ${ }^{9}$ Nach dem ersten Circular vom Februar 1847 war an cin Betriebskapital von höchstens 10000 Talern gedacht.

Jährlich sollten sechs Bände zu acht bis zehn Bogen erscheinen und zunächst nur geschlossen abgegeben werden. Der Ladenpreis einer jeden Serie war auf 1 Taler und 10 Groschen (=4 Mark) festgesetzt und konnte von privaten Subskribenten auch in Quartalsraten zu 10 Groschen bezahlt werden. Erst eine gewisse Zeit nach Erscheinen wollte man die Titel auch einzeln, jedoch zu einem »anschnlich erhöhten« Preis abgeben.

Die Resonanz im Buchhandel war für die Verlagsgründer wohl enttäuschend, denn nur 25 Sortimenter sowie Friedrich Volckmar als Leipziger Kommissionär beteiligten sich an dem Unternehmen. Springer und Simion, die sich ursprünglich mit nur $50 \%$ (oder weniger) hatten beteiligen wollen, mußten ihren Anteil auf fast $70 \%$ erhöhen. Bedenkt man allerdings die allgemein schlechte Wirtschaftslage des Jahres 1847, so war das Ergebnis gleichwohl noch akzeptabel. Immerhin hatten sich Gräfe \& Unzer, Königsberg, Hoffmann \& Campe, Hamburg, Wilhelm Hertz, Carl Heymann (mit zwei Anteilen), August Hirschwald und G. W. F. Müller, alle Berlin, beteiligt. Dies waren renommierte Firmen, deren Engagement zu Optimismus Anlaß gab. Einziger Ausländer war S. Höhr, Springers Zürcher Prinzipal. Für ihn mag es ein besonderer Anreiz gewesen sein, daß Gotthelf für das Unternehmen gewonnen worden war.

Die ersten drei Bände für das zu Ende gehende Jahr wurden im Oktober 1847 angekündigt und etwas später auch ausgeliefert: Gotthelfs >Käthi, die Großmutter ‘ in zwei Bänden, und $>$ Jacob Sturm< von Gustav Nieritz. Das Geschäft entwickelte sich zunächst noch relativ gut. Es zeigte sich allerdings, daß die Absatzerwartungen offenbar doch zu hoch angesetzt waren: Während von den Bänden des Jahres 1847 noch 8000 bzw. 10000 Exemplare gedruckt wurden, ging man schon im Folgejahr auf 6000 bis 8000 Exemplare zurück.

Das Geschäftsbuch weist für die ersten fünfzehn Monate 1847/48 zwar einen Gewinn von 1386 Talern aus, doch hierbei waren dic unverkauften Bestände offensichtlich zu hoch bewertet; dies zeigt auch die spätere Absatzentwicklung. Das Kapital und die Umsatzerlöse der ersten fünfzehn Monate reichten gerade aus, den Aufwand für Honorare und die Herstellkosten zu decken. Die Zukunft sah nicht sehr rosig aus. 
$\mathrm{M}$ it vielen seiner Veröffentlichungen war Springer bis an die Frech und unehrerbietig kann es nicht überraschen, daß die Zensurbehörde seine Aktivitäten mit geschärfter Aufmerksamkeit verfolgte. Springer wußte dies, doch er ging politischem Streit nicht aus dem Wege. Schon in der Schule hatte er als "kleiner Rebell« gegolten [MS: 2]. Als 1846 bei Chr. Th. Groos in Karlsruhe eine Broschüre >Über das Verbot ganzer Verlagsfirmen< von Heinrich Bernhard Oppenheimer erschien, lobte er das Buch in einer Börsenblatt-Rezension mit Enthusiasmus [20.11.1846]. Das Verbot ganzer Verlage, so referierte Springer, sei unhaltbar in einem Rechtsstaat. Verbote dieser Art seien schlimmer als ein Krieg, »denn sie sind ein Krieg ohne Kriegsrecht... sie sind nichts denn ein Produkt der Willkürherrschaft! Hiergegen kämpfe der Buchhandel schon seit Jahren, aber es sei im »Wesen der Willkür begründet, daß sie je länger je schrankenloser werden muß $\ll$. Er schloß seine Besprechung mit der Erwartung, daß die Broschüre »wirken wird und der Buchhandel wird sie gern in Kreise hin verbreiten, ... wo sie vielleicht zu Änderungen - im guten Sinne führt «.

Der Staatsanwalt des Königlichen Kriminalgerichts stellte Springer daraufhin »wegen des frechen unehrerbictigen Tadels preußischer Landesgesetze « unter Anklage, und am 27.4.1847 kam es zum Prozeß. Die inkriminierten Stellen waren unter anderem die Feststellung Springers, daß derartige Verbote »nichts als ein Produkt der Willkürherrschaft etc. « seien und daß $\gg$ durch Verlagsverbote Recht und Gesetz mit Füßen getreten $\ll$ würden. Springer verteidigte sich ungemein geschickt: »Eine Absicht seinerseits, Mißvergnügen der Bürger gegen dic Regierung zu erwecken, sei schon deshalb nicht anzunehmen, da das Börsenblatt nur für die Buchhändler berechnet, somit dem kleinsten Teile der preußischen Untertanen zugänglich sei.« Schließlich habe der Artikel auch »das Imprimatur des königlich-sächsischen Staates erhalten«. Mit List und juristischer Spitzfindigkeit verstand er es, die gegebene Rechtssituation zu nutzen. Offenbar waren die Richter Springer gewogen, denn sie sprachen ihn »nicht schuldig «.

Unter dem Datum der Gerichtsverhandlung publizierte Springer die Nachricht von seinem Freispruch am 1.5.1847 mit Genugtuung im Börsenblatt und hier auch am 18. Mai das fünf Spalten lange Urteil, das Springer unverzüglich nach Leipzig geschickt hatte. Aber der Staatsanwalt ging in die Revision. Bei der öffentlichen Sitzung am 18.9.1847 kam das Gericht zu der Erkenntnis, »daß der Angeklagte des Versuches eines Preßvergehens« schuldig sei, und Springer wurde zu drei Monaten 
19: Springer hatte zu früh triumphiert. Der Staatsanwalt ging in die Revision, und Springer warde zu drei Monaten Festungshaft verurteilt.
Prễ: \$rozef.

S̈egen ben unterzeidneten war Seitens des Róniglid)en Minifte=

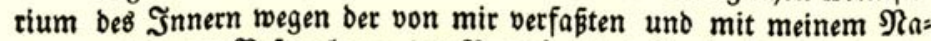
men verfebenen Befpred)ung Der Brod)úre bes Prof. Dppent)im in Şeibelberg "lueber baş

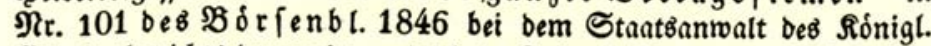
(Eriminalgerid)ts benuncirt und id) in Folge beffen wegen fred)en $\mathfrak{I a}_{a}=$

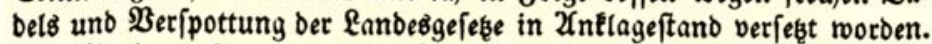

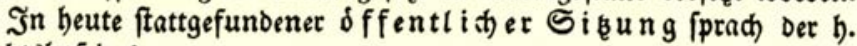
(Serichtżhof Dasి

ưber mid) aus.

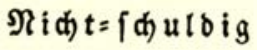

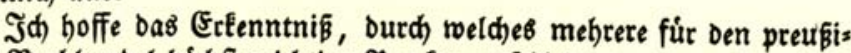
fden $\mathfrak{B u d}$ handel bod)ft wid)tige Punfte entf(bieden werben, febr bald vollftánoig mittheilen zu fỏnnen.

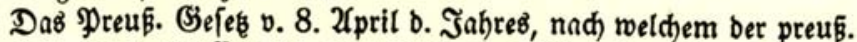
unterthan burd) bie (Senjur eines nid)t=preusifacen beutiaden Staates nid) $t$ mibr gefdúg unjerm Bórjenblatt in eine ganz veránderte Stellung gebradbt.

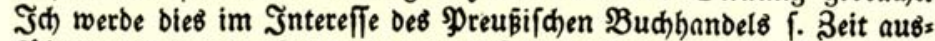

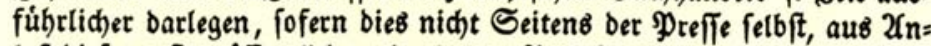

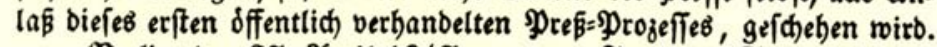

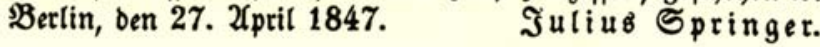

Festungshaft verurteilt. Er legte sofort beim Geheimen Obertribunal Berufung ein, doch sie blieb ohne Erfolg.

Springer stand monatelang unter dem Druck der gegen ihn erhobenen Anklage und der Appellation und bangte täglich, ob das Urteil der 3. Instanz wohl vollstreckt werde. »Drei Monate seiner Freiheit beraubt $z$ u sein «, schrieb er noch am 29.2.1848 an Gotthelf, »ist ein böses Ding und bleibt immer eine Fatalité, die aber den Charakter, denke ich, doch stärken wird.«Im selben Brief berichtet er Gotthelf, daß ihm gerade nähere Mitteilungen über die Vertreibung des französischen Bürgerkönigs Louis Philippe und die Proklamation der Republik zugegangen seien. »Gott behüte uns vor den Folgen dieses nicht erwarteten Ereignisses. « Es sind Zweifel angebracht, ob Springer gerade in dieser Situation dic kommenden Ereignisse wirklich fürchtete. Viel wahrscheinlicher ist es, daß er angesichts der sich auch in Berlin zuspitzenden Situation seine Hoffnungen in eine politische Wende setzte.

Als ihm das Urteil am 18.3.1848 mit der Aufforderung zugestellt wurde, sich innerhalb von zehn Tagen zur Verbüßung seiner dreimonatigen Haftstrafe in der Festung Magdeburg einzufinden, waren die Würfel in Berlin schon gefallen. Zwei Tage später fiel das über ihn verhängte Urteil unter die Amnestic. 
$\mathrm{W}$ erner Siemens, der in diesen Tagen gerade damit beschäftigt war, sich an einem Wettbewerb über dic Verlegung von Telegraphenleitungen zu beteiligen, schrieb später über die ereignisreichen Märztage: »Mit elementarer Gewalt brauste der mächtige Strom der politischen Aufregung dahin und riß alle die schwachen Dämme nieder, welche die bestehenden Gewalten ihr ziel- und planlos entgegenstellten. Die Unzufriedenheit mit den herrschenden Zuständen, das Gefühl der Hoffnungslosigkeit, daß sie sich ohne gewaltsamen Umsturz ändern licßen, durchdrang das ganze deutsche Volk und reichte selbst bis in höhere Schichten der preußischen Zivil- und sogar Militärverwaltung.... Die Straßen Berlins wurden ununterbrochen von erregten Menschen durchflutet, die sich gegenseitig die übertriebensten Gerüchte über den Fortschritt der Bewegung in Deutschland mitteilten und überall improvisierten Volksrednern zuhörten, welche sie verbreiteten und zu gleichen Taten anfeuerten « [SIEMENS: 46f.].

In der Breiten Straße wurde eine Barrikade zwischen dem Köllnischen Rathaus und der gegenüberliegenden $>$ Schloßklause< errichtet, und auch in der Roßstraße, wo die Familie Springer wohnte, wurde gekämpft. »Fürchterlich war die Nacht des Kampfes vom 18. zum 19. (März), « schreibt er am 27.3. an

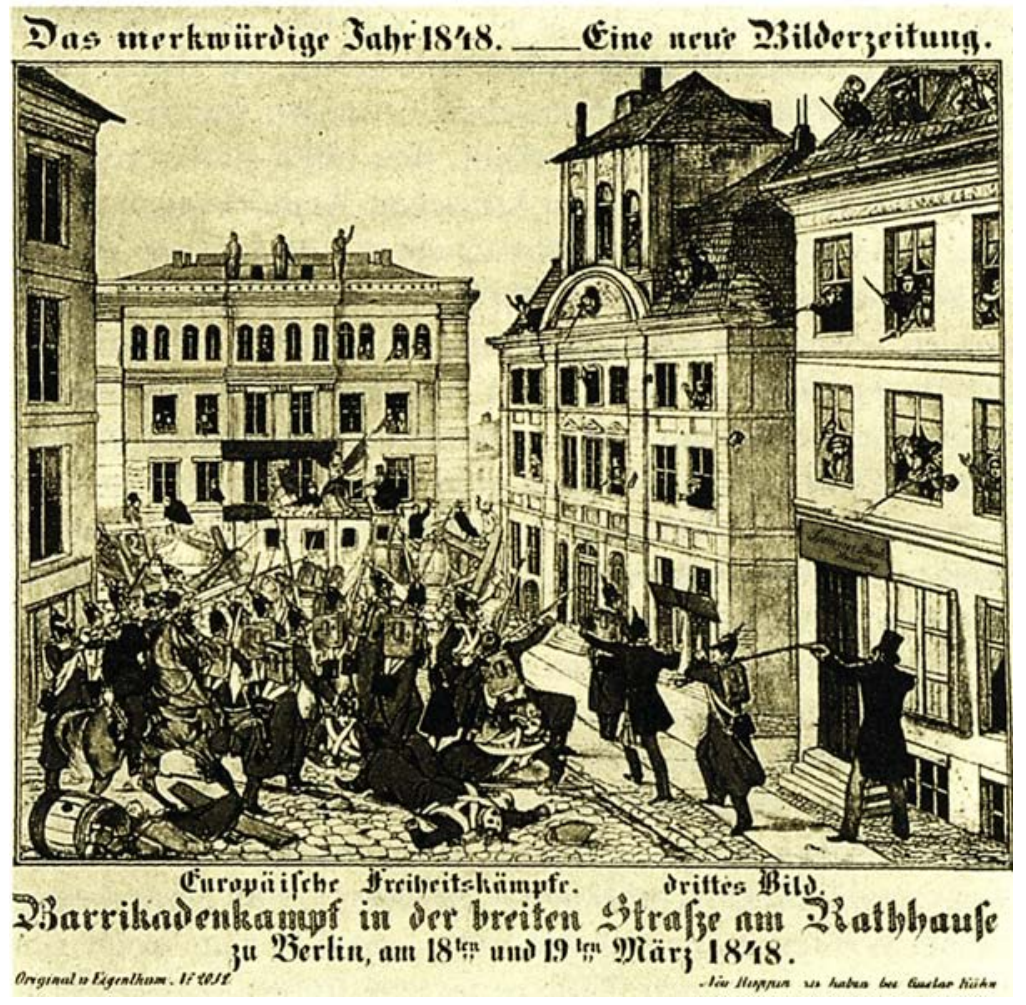

Die Revolution von $1848 / 49$

20: Barrikadenkampf in der Breiten Straße, unmittelbar vor dem Rathaus und vor Springers Buchhandlung (rechts). In einem Brief an Gotthelf hat Springer die Nacht vom 18. auf 19. März, recht dramatisch geschildert. Seiner Frau blieb aus den nun folgenden Wochen in Erinnerung: "Es kam die Zeit der Bürgerwehr, wo wir nachts alarmiert wurden und ich Kaffee kochte und ihn nach der Spittelmarktwache schickte, wo mein Mann, der keine Ahnung vom Militärdienst hatte, als Zugführer mit dem Kavaleriesäbel meines Vaters figurierte. Ich nahm alles heiter hin..." [MS: 26f./. 
21: Diese 16seitige Flugschrift, im Frühsommer 1848 erschienen, sollte der Aufklärung über die Ziele der Revolution dienen. Im Vorwort schreibt der Autor: »Von allen Seiten her gehen uns Nachrichten zu, welche beklagen, dafs besonders der Landmann und der Bürger in den kleinen Städten die Vorzüge unserer neuen Zustände gar nicht begreife, sondern in den Folgen unserer Staatsumwälzung nur Verderben für sich und das Land fürchte. Für diese Männer nun versuche ich, die gestellen Fragen zu beantworten.

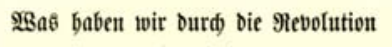
verloren? -

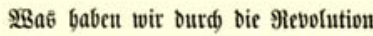
getwounen? -
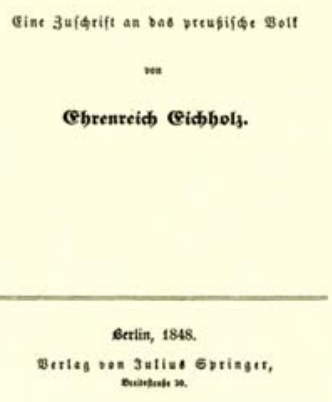

Gotthelf. »Unsere Wohnung ist dicht an einer mutvoll und siegreich verteidigten Barrikade gelegen, und wir hatten selbst für unser Haus alles zu befürchten. Dabei schliefen die Kinderchen in süßester Unschuld, und dieser Kontrast zwischen dem tobenden Kampf auf den Straßen und dieser süßen Ruhe war herzzerreißend!«

In diesen Tagen war Gotthelfs $>$ Uli, der Pächter gerade in Druck gegangen. Zwar konnte Springer seinem Autor am 23. März noch mitteilen - »in aller Eile und das Gewehr zur Seite $\ll-$, daß die Arbeit wieder aufgenommen werde, doch schon am 27. März kam er nicht umhin, seinen Autor auf weitere Verzögerungen einzustimmen: »Es ist mir eigentlich lieb, daß wir mit unserem zweiten Teil des Uli noch nicht weiter sind; es wird langer Zeit bedürfen, ehe das Interesse für Literatur überhaupt und Volksschriften Ihrer Art insbesondere wieder ein reges wird, wenn schon ich mich überzeugt halte, daß bei zurückgekehrter Ruhe und sicherem Bestehen freilich sehr veränderter Verhältnisse so genannte bürgerliche Volksschriften ihre Geltung und Wert gerade so recht erhalten werden.«

Am 5. Mai kommt Springer auf Nebenerscheinungen der Revolution zu sprechen, die sein Geschäft auch unmittelbar betrafen. Die Buchdrucker hatten höhere Löhne verlangt und da »die Prinzipale nicht zahlen konnten,... so wurde hier acht Tage lang weder gedruckt noch gesetzt $\ll$. »Ob die nicht $\mathrm{zu}$ ihnen [den Buchdruckern] gehörenden untergehen, ist ihnen ganz gleich, wenn sie nur besser bestehen. « Auf den Wahlversammlungen habe er sich nicht gescheut, dies offen auszusprechen. Zunächst habe er mit seinen kritischen Anmerkungen einen fürchterlichen Sturm heraufbeschworen, doch Tags darauf (5. Mai) sei er zum Wahlmann für Berlin und Frankfurt gewählt worden. »Meinem Geschäfte vermag ich gar nicht vorzustehen, so nehmen mich die öffentlichen Angelegenheiten und die in ihnen übernommenen und überkommenen Pflichten in Anspruch. Es ist eine große, ganz neue Zeit, in der wir leben; es ändern sich alle Verhältnisse und Beziehungen der Menschen im Staatenverbande, wir sind in der größten Revolution, welche menschliche Verhältnisse bisher erfahren - tun wir das unserige, daß unsere Errungenschaften von Wert werden!«

In der Stadtverordnetenversammlung wird Springer das Amt des Schriftführers übertragen. Er ist damit zugleich der Stellvertreter des Vorsitzenden und hat neben den ihm hiermit zugewachsenen Aufgaben einmal in der Woche der Versammlung seines Bezirks zu präsidieren. Springer nimmt beide Ämter mit allem Eifer seiner 31 Jahre wahr, und die »dem Wohle des Allgemeinen gewidmete Zeit« reicht vom frühen Morgen bis in 
die späte Nacht. Aus diesem täglichen Kontakt mit Liberalen und Demokraten entstehen freundschaftliche Verbindungen, die Springer bis an sein Lebensende pflegte. Viele dieser Mitstreiter sind bald mit Publikationen im Programm des Verlags vertreten. So geht die Gewinnung des Staatsrechtlers Rudolf Gneist in diese Zeit der politischen Debattier-Clubs zurück, und Springer bekommt auch den ersten Kontakt zu Johann Jacoby (s.S. 49f.), der in diesen turbulenten Monaten seine Briefe zu Händen Springers adressieren läßt.

Es kennzeichnet Springer als Verleger, daß er in dieser revolutionären Zeit auch durch rasch produzierte Flugschriften zu wirken trachtet. Es sind dünne Hefte, häufig nur einen Druckbogen von 16 Seiten stark. Sie sind hastig gefalzt, nicht geheftet und bedurften auch keines Umschlags. Diese Flugschriften sind für den Tag geschrieben und gleichen mehr Leitartikeln denn Aufsätzen. In dieser unruhigen Zeit erscheinen aber auch drei Titel der Volksbibliothek mit zusammen fast 1000 Seiten, trotz Streiks und Unruhen, gestörter Verkehrsverbindungen und allgemeiner Geldnot. Bei aller Skepsis, daß eine Wandlung der Publikumsneigungen eintreten werde, vertraut er auf die Wirkung seines Autors Gotthelf, von dem er in diesem Jahr allein für den Volksschriften-Verein fünf Bände herausbringt (>Hans Joggeli< und >Leiden und Freuden eines Schulmeisters $<$ in vier Bänden).

Gotthelf allerdings, der die politischen Vorgänge in Deutschland mit Unbehagen verfolgte und offenbar Hinweise auf die Störungen des Wirtschaftslebens nicht gelten ließ, nahm die verzögerte Überweisung seines Honorars von 400 Talern für die >Leiden und Freuden $<$ zum Anlaß, dem Volksschriften-Verein künftig keine weiteren Manuskripte mehr zu überlassen.

Im November 1848 wurde >Uli, der Pächter ^fertiggestellt. Springer warnte seinen Autor aber schon bei der Übersendung der Freiexemplare vor zu hohen Verkaufserwartungen: »Die Hoffnungen, welche Sie an das Erscheinen... knüpfen, kann ich unter den gehemmten Verhältnissen der Gegenwart für die nächste vor uns liegende Zeit nicht teilen «, schreibt er am 26. November. »Wir büßen im Augenblick für viele kleine begangene Sünden, deren Wirkung lediglich unser augenblicklicher Zustand der Gewalt und Gesetzlosigkeit von oben ist, während [es] seit dem März derselbe von unten war. Ich hoffe, wir werden auch hieraus lernen und bei dem neuen freieren Aufschwunge unseres politischen Lebens nicht in die alten Fehler fallen.«

Mit dem Einzug der Truppen General Wrangels fand die Revolution in Berlin ihr Ende. Der Gemeinderat hatte acht Tage

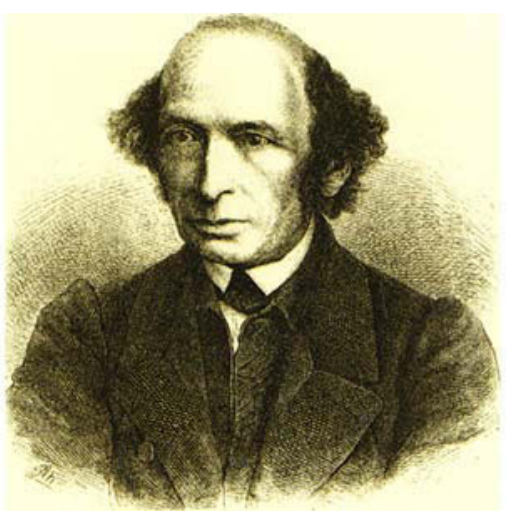

22: Johann Jacoby (1805-1877), linksradikaler Politiker. Als Mitglied einer Deputation des Berliner Parlaments rief er bei einer Audienz in Potsdam am 2.11.1848 dem sich abwendenden König Friedrich Wilhelm nach: »Das ist das Unglück der Könige, daß sie die Wahrheit nicht hören wollen!", ein Wort, das in Berlin rasch die Runde machte. 
in Permanenz getagt, und so ruhten bei Springer die Geschäfte. Nachdem die Obrigkeit am 5.12.1848 eine Verfassung >oktroyiert< hatte, zogen sich die Bürger in ihr privates und geschäftliches Leben zurück, teils zornig, teils entmutigt; nicht wenige kehrten auch reucvoll zur alten Ordnung zurück. Tausende aber emigrierten in die Schweiz, nach England, Frankreich oder ins ferne Amerika.

Aber Springer resignierte nicht: »Der Blüte meines Etablissements ist zwar manches Blatt im Sturme der Zeit abgefallen, aber dic Blüte ist nicht gebrochen. Lediglich die großen $\mathrm{Au}$ Benstände, die bei der so geldklammen Zeit nicht schwinden, machen mir Sorge, weil ich darein mein Vermögen schwinden sehe« [Gotthelf: 26. 11. 1848].

In Haft wegen Preßjergehens

23: Georg von Vincke (1811-1875), im preußischen Abgeordnetenhaus Fiihrer der freisinnigen Mehrheit, wandte sich vehement gegen die nachgiebige Haltung Preußens in der deutschen Frage (Olmütz) und gegen die Parole »Der Starke tritt einen Schritt zurück«. Springer veröffentlichte Vinckes Rede vom 3.12.1850 mit groß3em Erfolg.

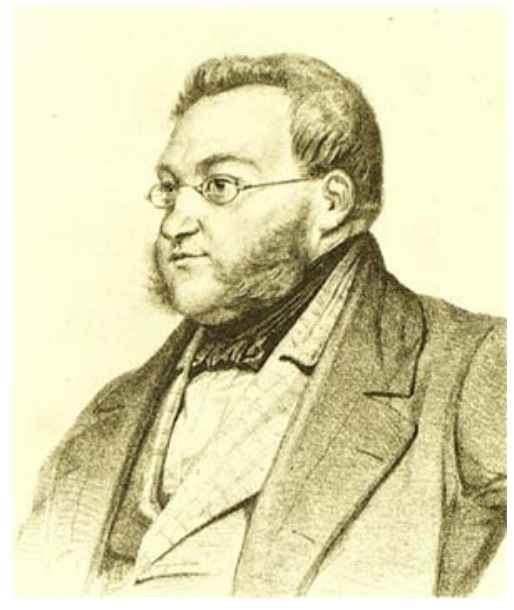

$\mathrm{T}$ agespolitische Schriften hatten dem Programm Springers im Vormärz seinen Akzent gegeben. Nun wurde er vorsichtiger. Noch im Dezember 1850 hatte er die aufsehenerregende Rede veröffentlicht, dic Georg von Vincke am 3.12.1850 vor der Zweiten Kammer gehalten hatte, »wortgetreu nach den stenographischen Berichten«, wie er es für angebracht hielt, dem Titel hinzuzufügen. Vincke war der führende Kopf in der liberalen Opposition und hatte sich in einer vehementen Rede gegen die Regierung Manteuffel gewandt, die in der Forderung gipfelte: »Weg mit diesem Ministerium! « Das war in dieser Zeit in Preußen eine unerhörte Kühnheit. »Da war der Andrang des Publikums zur Buchhandlung so groß, « schreibt Marie Springer, »daß Chaine gemacht und Polizei requiriert werden mußte, um Ordnung vor der Tür zu halten « [MS: 34]. Daß man vor seiner Buchhandlung Schlange stehen mußte, ließ Springers Herz höher schlagen. Noch im selben Monat mußte er drei Nachdrucke folgen lassen. Es war dies für Springer eine recht gewagte Veröffentlichung, denn cinige Monate zuvor hatte er sich (wieder cinmal) mit der Zensur angelegt:

Am 4.6.1850 hatte die Polizei in seiner Abwesenheit zwei Exemplare des bei Raabé \& Co. in Kassel erschienenen Buches >Das Preußentum und die hohenzollernsche Politik < beschlagnahmt. Da die Staatsanwaltschaft eine $\gg$ im Sinne des Gesetzes verantwortliche Verbreitung « unterstellte, wurde Springer zwei Wochen später in seiner Buchhandlung verhaftet und für acht Tage im Stadtgefängnis arretiert. Man berief sich auf die preuBische Preßverordnung vom 30.6.1849, in der es in $\S 12$ hieß: »Für den Inhalt einer Schrift sind der Verfasser, der Verleger, der Drucker, der Verbreiter als solche verantwortlich, ohne daß es eines weiteren Nachweises der Mitschuld bedarf. Jedoch darf 
keine der in der obigen Reihenfolge nachstehenden Personen verfolgt werden, wenn eine in derselben vorstehenden Personen im Bereiche der preußischen richterlichen Gewalt ist « [GorTHELF: 15.7 .1850$]$.

\section{12.}

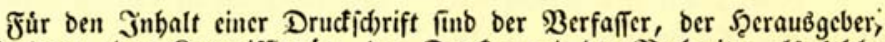

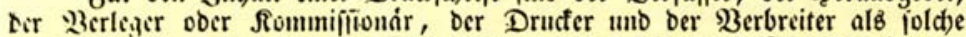
verantmortlid), ofne ठаß

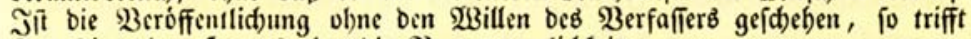

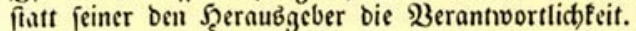

(Es Darf jeDod) feine ber in obiger Reibenfolge nad)ftelsenden Yerfonen verfolgt rerben, wenn cine ber in bericiben vorftefenden $\mathfrak{D e r j o n e n}$ befannt und in bem 23ereid)e ber rid)terlid)en (Servalt oes Etnates ift.

Dicie 2 cefiummung ftel)t ber gleid)zeitigen 2 erfolgung berjenigen nid)t

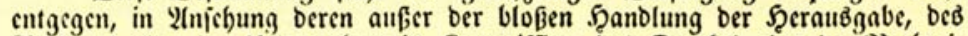

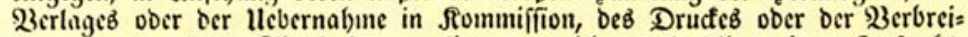
tung, nod) anbere Thatfad)en vorliegen, weld)e nach allgemeinen frafrecbt= lidben (Brunbfäben eine wiffentlid)e Theilnabme an ber burd) bie Drudfid)rift begangenen frafbaren Şanblung begrúnben.

Springer war in diesem Fall also dic letzte der $\gg$ nachstehenden Personen «; die »vorstehenden Personen« waren nicht »im Bereiche der preußischen richterlichen Gewalt«. Da ihm eine Verbreitung nicht nachgewiesen werden konnte, wurde das Verfahren eingestellt. Springer versäumte nicht, dem Buchhandel unverzüglich die Umstände seiner Verhaftung - per Absender »Berlin, Hausvogtei d. 22. Juni 1850«- und auch seine erfolgte Freilassung im Börsenblatt mitzuteilen. Es war nun erhöhte Vorsicht geboten, zumal ein 1851 in Dresden gegründeter $>$ Polizeiverein der bedeutenderen deutschen Staaten< alle als oppositionell geltenden Verleger zu kontrollieren begann [SIEMANN].

$\mathrm{S}$ pringer setzte seine Bemühungen, die Verlagsrechte auch aller früher erschienenen Bücher Gotthelfs zu erwerben, mit Erfolg fort, obwohl er bemerkt hatte, daß die Sympathien des Publikums für seinen Autor schon im Schwinden begriffen waren. Anfang 1852 erschien dann >Zeitgeist und Berner Geist<. Es war dies ein "in seiner Tendenz unzeitgemäß konservatives und zudem polemisches Werk «[ANDERMATT: 55]. Schon vor der Veröffentlichung hatte Springer sein Urteil gegenüber Gotthelf ungeschminkt ausgesprochen: $\gg$ Das Buch ist fast eine reine Parteischrift, es fehlt ihm, mit Ausnahme einiger herrlicher Kapitel, jene Seelenmalerei, die Ihre anderen Schriften auszeichnct! Eine Zukunft hat dies Buch sicher nicht, und in Deutschland namentlich wird es selbst bei Ihren Freunden nicht gefallen! « (21.11.1851). Und als die ersten negativen Kritiken vorlagen,
24: Springer zitierte in seinem Brief an Gothelf den Text des $\$ 12$ der Preufischen Preßverordnung vom 30.6.1849 zwar nicht wortgetreu. doch dem Sinn nach korrekt.
Weiterhin Favorit:
Jeremias Gotthelf 


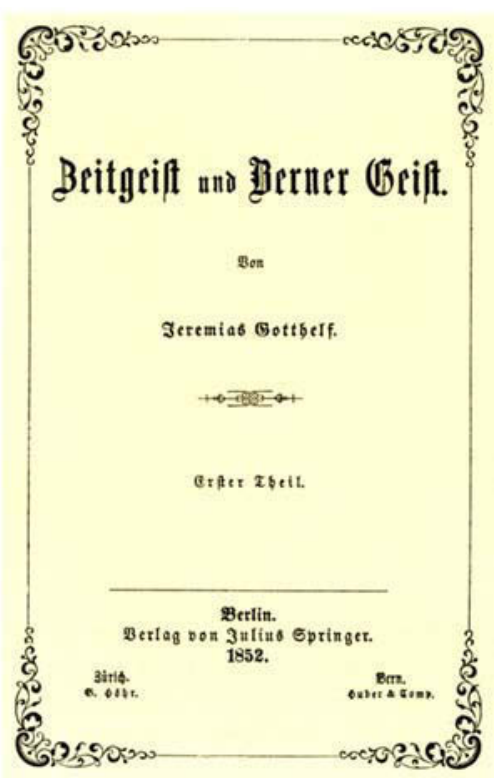

25: , Zeitgeist und Berner Geist war eine konservative Kampfschrift Gotthelfs. Springer legte seinem Autor nahe, Parteienzwist doch besser in den Zeitungen seines Landes auszutragen. sieht er seine Ahnungen bestätigt: »Der Herr Pfarrer Bitzius hat schon recht, seiner Partei zu helfen und sie zu schützen. Ich weiß aber, daß das nicht zu trennen [ist] und bedaure nur, daß Ihren schriftstellerischen Leistungen das Parteiwesen so anklebt. Das Urteil der Grenzboten, das ich Ihnen sandte, wiederholt sich durch die ganze Journalistik und in den Kreisen Ihrer Freunde... Kämpfen Sie doch ihre Parteiungen in Ihren Journalen dort aus « [GoTTHELF: 1.3.1852].

Schließlich mußte Springer sich gar noch gegen Gotthelfs Vorwurf wehren, er habe z.B. dadurch, daß er nur feindlich gesonnenen Rezensenten Besprechungsexemplare geschickt habe, zum schlechten Absatz selbst beigetragen. Er irre sehr, schreibt er seinem Autor am 24.8.1852, wenn er in ihm einen Verleger radikaler Schriften sehe. »Mein politisches Glaubensbekenntnis habe ich Ihnen weder noch sonst jemandem verschwiegen, aber es wäre närrisch von mir, nur Bücher von Autoren verlegen zu wollen, welche meine politischen Ansichten teilten. Es gab eine Zeit, wo dies Mode - aber auch weiter nichts war. Das einzige, worauf ich als Verleger zu sehen habe, ist, daß der sittliche Standpunkt der Autoren dem meinigen entspricht und hier werde ich mir nie etwas vergeben, weil ich mich dadurch erniedrigen würde! «

Eineinhalb Jahre später, am 15.10.1853, muß sich Springer erneut gegen den Vorwurf der Vernachlässigung von >Zeitgeist und Berner Geist < zur Wehr setzen: »Wie wenig kennen Sie Tun und Lassen eines Verlegers! Ich habe es gerade bei diesem Buche, abgesehen von bezahlten Ankündigungen, an Verteilung von Freiexemplaren an literarische Institute und Persönlichkeiten nicht fehlen lassen. Nun schießen Sie aber gar noch weiter und meinen, ich täte für Bekanntwerden und Vertrieb Ihrer Bücher überhaupt nicht genug! Das ist der härteste Vorwurf, der einem Verleger gemacht werden kann und der ungerechteste, der gerade in Bezug auf Ihre Schriften mir gemacht wird.«

Springer hatte gewiß nicht zu schwarz gemalt, denn das Interesse gerade an diesem Buch war so gering, daß noch 60 Jahre später die Erstausgabe lieferbar war. Die negative Wirkung von >Zeitgeist und Berner Geist< hatte auch entsprechende Folgen für den Absatz der anderen Bücher des Dichters. So sieht sich Springer genötigt, von künftigen Ausgaben nur noch 2000 Exemplare drucken zu lassen (bis dahin waren es 3000 oder gar 3500 Exemplare gewesen) und das Honorar entsprechend zu senken. Gotthelf wird dies kaum goutiert haben, aber er fügte sich. Immerhin zahlte Springer trotzdem noch Honorare, die für jene Zeit ungewöhnlich hoch waren [ANDERMATT: 31]. 


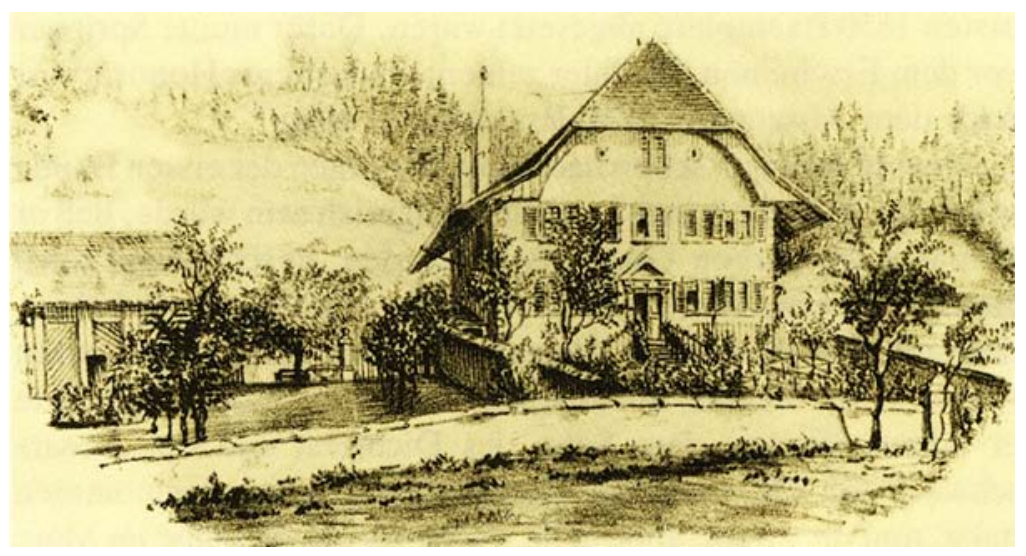

Bei aller Schärfe, die in der Korrespondenz zu bemerken ist, verstand es Springer, seinen Standpunkt stets offen zu vertreten, ohne damit einen Abbruch der Bezichungen zu riskieren. Die Diskusion war im Frühjahr 1854 allerdings an einem Punkt angelangt, der es ihm geraten erscheinen ließ, seine häufig geplante und immer wieder verschobene Schweizer Reise nun endlich anzutreten. Bei dieser Gelegenheit sollten auch verbindliche Absprachen über die seit Jahren geplante Gesamtausgabe getroffen werden, obwohl Gotthelf zu dieser Zeit kaum mehr ein besonderes Interesse beim deutschen Publikum fand. Aber die Bemühungen um eine Gesamtausgabe waren für Springer eine $\gg$ Herzensangelegenheit $«$; dies hatte er dem Dichter schon am 19.2 1849 geschrieben. Das kaufmännische Kalkül stand jedenfalls nicht im Vordergrund seiner Überlegungen. Freunde hatten ihm zur Vorsicht geraten, und der Krim-Krieg, der Preußen in seinen Strudel zu ziehen drohte, ließ eine wirtschaftliche Flaute befürchten. Nur cin persönlicher Besuch konnte Klarheit schaffen.

Als Springer dann Ende Juli 1854 für vier Tage in Lützelflüh weilte, verstanden sich die beiden Männer schon auf den ersten Blick. In einem ausführlichen Brief schilderte Springer seiner Frau die Tage im Pfarrhaus [MS: 142ff.]. Es kam zu einem Kompromiß: Die Auflage sollte 3000 Exemplare betragen, wobei zunächst nur eine Serie von 12 Bänden vorgesehen war. 1500 Taler sollten bei Erscheinen und der Rest von 1000 Talern nach dem Verkauf von 1850 Exemplaren fällig werden.

Doch Gotthelf starb am 22.10.1854, drei Monate nach Springers Besuch. Auch wenn es nicht mehr zu einer schriftlichen Vereinbarung gekommen war, stimmte Gotthelfs Witwe den ihr im Grundsatz bekannten Bedingungen zu. Allerdings wurde nun der Vertrag auf 24 statt auf 12 Bände geschlossen; die zweite Seric von 12 Bänden sollte erst gedruckt werden, wenn von der
26: Für einen Abzug dieser Lithographie des Pfarrhauses in Luitzelflïh bedankte sich Springer am 23. 4.1850 bei Gotthelf: »Sie hängt eingefaßt Ihrem Porträt gegenüber, und ich kann nur wünschen, daß. es mir einmal vergönnt ist, Sie dort selber zu sehen und kennen zu lernen ..... Springers Besuch in Liutzelflüh erfolgte dann erst vom 18. bis 21.7.1854, drei Monate vor dem Tod des Dichters.

27: Umschlagzeichnung von Ludwig Pietsch für eine , Miniaturausgaber. "Der damals unbekannte junge Maler war noch nicht aus unserem Norden herausgekommen und holte sich bei uns Rat zur Ausfïhrung der Schweizer Trachten and Gerätschaften in Wort und Bild« [MS: 49]. Springer zahlte für solche Illustrationen 4 bis 6 Taler.

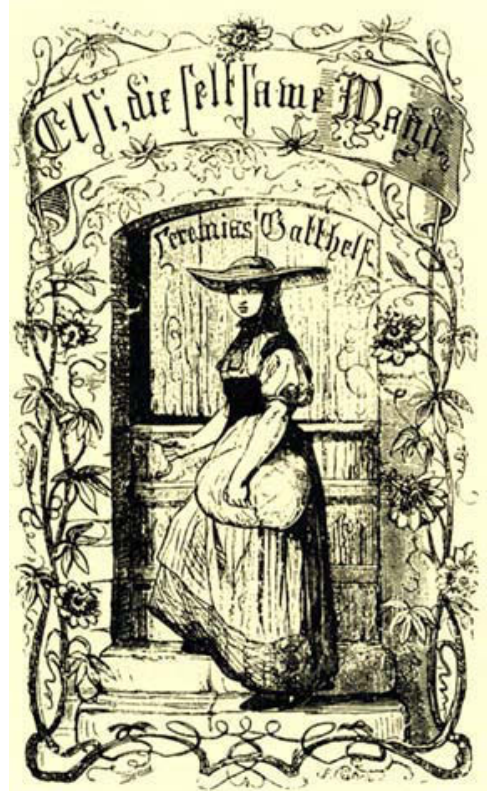




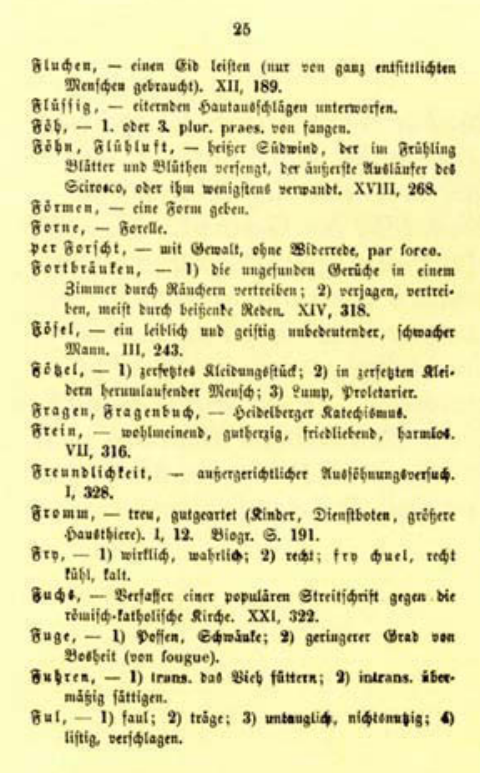

28: Dem 23. Band von Gotthelfs Gesammelten Schrifien wurde 1858 eine 103 Seiten amfangreiche. - Erklärang der schwierigen dialektischen Ausdrücke angefügt, die auch separat erschien. Der Pfarrer Albert von Rütte, ein Schwiegersohn des Dichters, schrieb in scinem Vorwort. daß Gothelf der Meinung gewesen sei, »das speciell Bernische in der Sprachweise dürfe nicht allzusehr preisgegeben werden, wenn nicht um der Form willen der Inhalt wiber Gebühr leiden solle

29 (gegenüberlicgende Seite): Eine Seite aus Springers Geschäftsbuch (stark verkleinert) mit den Aufwendungen für das Papier etc. der Gesammelten Schriften Gotthelfs. Preisangaben in Taler, Groschen und Pfennig. ersten 1850 Exemplare abgesetzt waren. Dafür mußte Springer vor dem Erscheinen 800 Taler zahlen; ein weiteres Honorar war nach dem Absatz von 1850 Exemplaren fällig.

Obwohl Springer schon nach dem Vorliegen der ersten Bände erkannte, daß die Ausgabe nicht erfolgreich sein würde, ließ er sich von den Erben Gotthelfs überreden, anschließend auch gleich die zweite Serie herzustellen. Er mochte gehofft haben, daß sich die vollständige Ausgabe insgesamt besser verkaufen würde. Doch dies war ein Trugschluß. Am 25.5. 1857 berichtete er Albert Bitzius, dem Sohn des Dichters, daß der Absatz schwach sei und mancher, der die erste Serie abgenommen habe, nun die zweite abbestelle. Auch als die Ausgabe im März 1858 komplett war, belebte sich der Absatz nicht.

Springer versuchte nun, seine Investitionen durch eine stark verbilligte Ausgabe wieder hereinzubringen: Über die Dalp'sche Buchhandlung in Bern brachte er eine $>$ Neue wohlfeile Ausgabe auf den Markt, für dic cr lediglich neue Titelblätter drucken ließ. Doch selbst die Senkung des Preises von 70 auf 36 Schweizer Franken brachte keinen Auftrieb. Daß er von dieser Aktion nicht sogleich die Erben verständigt hatte, führte dann zu ärgerlichen Mißverständnissen. Diese fühlten sich getäuscht, weil sie meinten, Springer habe schon eine zweite Auflage gedruckt. Doch die Familie ließ sich von des Verlegers redlichen Absichten überzeugen und sanktionierte nachträglich dessen Vorgehen und Vorschläge, die auch eine Reduktion des Honorars einschlossen.

1860 standen den Herstellkosten in Höhe von 13163 Talern nur 9353 Taler an Erlösen gegenüber. Von der ersten Serie waren 978 Exemplare, von der zweiten gar nur 760 verkauft worden. Zur Deckung seiner Kosten wäre mindestens der Verkauf von je 1500 Exemplaren nötig gewesen. Über 50 Jahre später, als der Verlag sein neues Verlagshaus in der Linkstraße bezog (1911), war die >Neue wohlfeile Ausgabe immer noch lieferbar, obwohl die 24 Bände zu cinem nochmals auf 28,80 Mark reduzierten Preis angeboten wurden. Wie es heißt, wurde dic Ausgabe bald nach dem Umzug »verschenkt «. Der Verlag brauchte Platz für die schon seit Jahrzehnten in ganz anderen Bahnen verlaufende Produktion.

Springers Verdienste um Gothelfs Werk sind unbestritten. Wenn hier ausführlicher über den Kontakt zu seinem schwierigsten Autor berichtet wurde, so sollte gezeigt werden, wie unbeirrbar Springer sich für den von ihm hochgeschätzten Dichter cingesetzt hat und daß er sich weder durch Meinungsverschiedenheiten noch durch wirtschaftliche Einbußen beeinflussen ließ. Die Gotthelf-Ausgabe war für Springer auch ein 


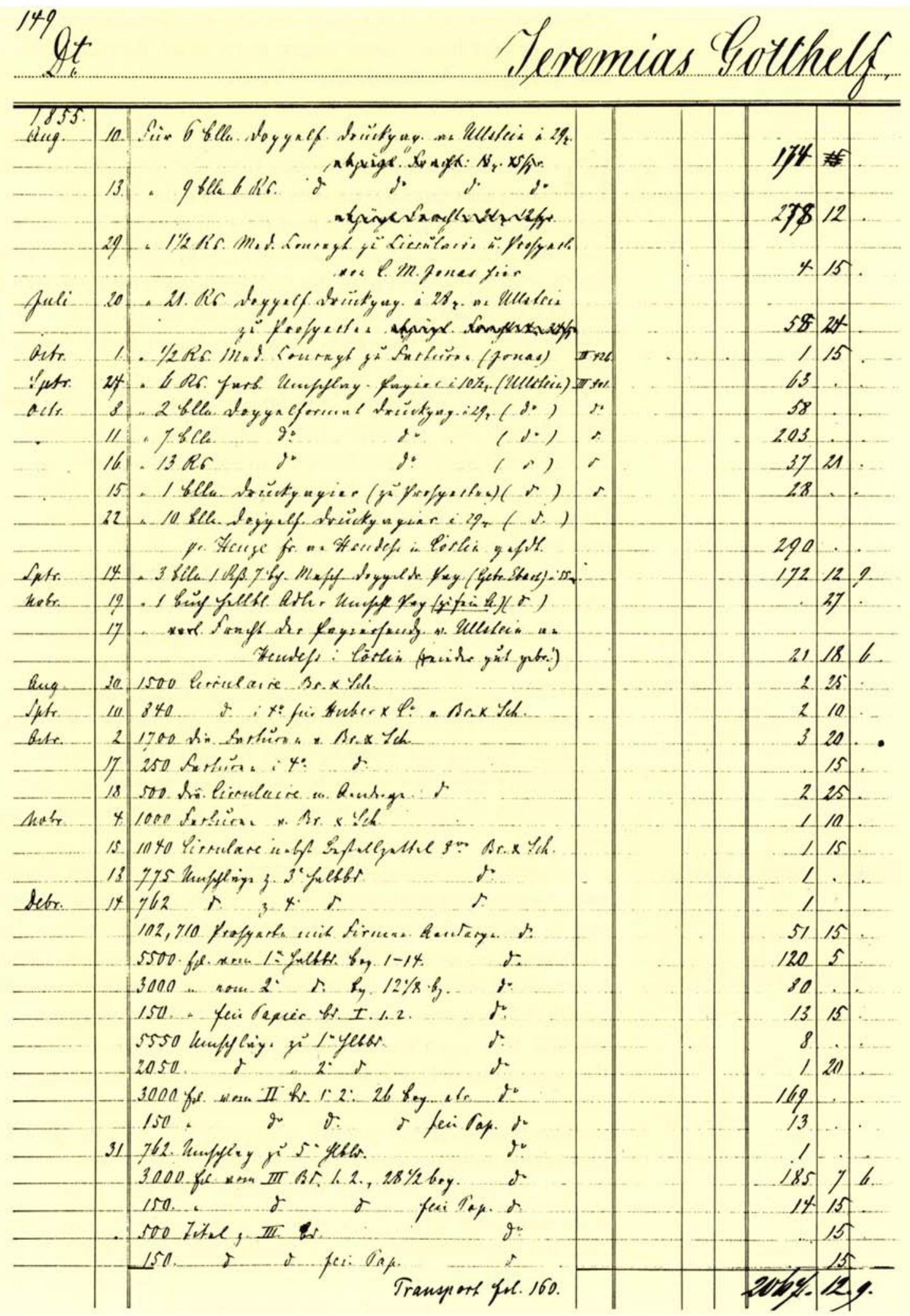


30: Onkel Tom's Hütte von Harriet Beecher-Stowe war schon im Jahr des Erscheinens der amerikanischen Erstausgabe auch in Europa ein großer Bucherfolg. Springers dreibändige Ausgabe erschien Ende November 1852, doch sie war nicht die einzige am Markt.

\section{Oukel Com's Gü̈tte.}

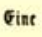

Pegergef d $i$ d t te
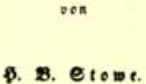

Griter Bants.

Bettin, 1852.

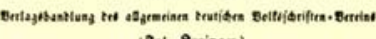

(3at. 8pringre)
Abschied von der $>$ Literatur $<$, mit der er insgesamt nur wenig Glück gehabt hatte. Dies zeigen auch seine Bemühungen um den Verlag des Volksschriften-Vereins.

Ende des

$\mathrm{D}$ as Geschäftsjahr 1847/48 war trotz der revolutionären Unruhen und der allgemeinen Geldverknappung noch relativ gut verlaufen, doch das Unternehmen mußte sich auf einen insgesamt geringeren Absatz cinstellen, ohne dic Verkaufspreise erhöhen zu können. Hatten die Auflagen zunächst noch 6000 bis 10000 Exemplare betragen, so gingen sie bis 1851 auf 1500 bis 2000 zurück. Das Geschäft kann also kaum mehr profitabel gewesen sein.

Ein schwerer Schlag war es dann für das junge Unternehmen, daß Simion als Verleger des verbotenen >Brennglas'schen Volkskalenders $<$ die Konzession entzogen wurde und man sein Geschäft am 15.1.1852 polizeilich schloß. Simion wich nach Leipzig aus, und die alleinige Leitung des Unternehmens lag nun bei Springer.

Ein relativ erfolgreiches Buch war Harriet Beecher-Stowes >Onkel Tom's Hütte<. Als die Ausgabe des VolksschriftenVereins Ende November 1852 crschien, lagen allerdings schon zehn andere deutsche Übersetzungen vor (in England gab es sogar 20 Ausgaben!). Die amerikanische Buchausgabe war zwar erst am 20.3.1852 in Boston erschienen, da aber der Text schon seit Juni 1851 in der Washingtoner Zeitung > The National Era< abgedruckt worden war, hatten sich deutsche Verleger die Zeitungsfolgen unverzüglich beschafft und zur Übersetzung gegeben.

Springer pries zwar seine vorzügliche Übersetzung, die sehr gute Ausstattung und den günstigen Preis, aber seine Ausgabe kam zu spät, und einige andere waren noch preisgünstiger. Dennoch konnten etwa 3000 Exemplare verkauft werden. Höhere Verkaufszahlen hatten nur noch die Bücher Gotthelfs mit 4000 bis 5000 Exemplaren gehabt. Dieser verhältnismäßig gute $\mathrm{Ab}$ satz war aber auch teuer erkauft: Springer bot die Ausgabe bei Abnahme von 13 Exemplaren, von denen nur 12 berechnet wurden (also >Partie 13/12<), zu einem Sonderpreis von nur 4 Talern an. Das bedeutete bei einem Ladenpreis von 20 Silbergroschen für die dreibändige Ausgabe einen Rabatt von 54\%! Im Einzelverkauf gab er $40 \%$ bei Barzahlung und bei Lieferung mit Rückgaberecht $25 \%$. Es konnte nun also jeder Sortimenter zu den Vorzugsbedingungen der Gesellschafter einkaufen, ohne zur Abnahme der ganzen Serie verpflichtet zu sein. Somit hatten die Kapitalgeber keinerlei Vorteile mehr. 
Große Hoffnungen hatte man auch in Friedrich Gerstäckers $>$ Der Wahnsinnige gesetzt. Entsprechend den hohen Absatzerwartungen wurden 5000 Exemplare gedruckt und ein Honorar von 300 Talern gezahlt. Abgesetzt wurden aber nur 856 Exemplare und hierfür 161 Taler erlöst. Um nur die Selbstkosten zu decken, hätten etwa 3000 Exemplare verkauft werden müssen. So blieb, nur unter Berücksichtigung der Herstellkosten und des Honorars, ein Verlust von 321 Talern [KNoche (1): 13].

Angesichts steigender Verluste wurden die Gesellschafter ungeduldig. Der Tod von Simion am 14.1.1854 brachte dann die Entscheidung, denn kein Teilhaber war bereit, dessen Geschäftsanteil zu übernehmen. So erfolgte am 1.6.1854 die Löschung der Firma, nachdem, wie zu vermuten ist, auf der letzten Generalversammlung, am 15.5. 1854, die Liquidation beschlossen worden war.

Die abgewerteten Bestände - es waren immerhin 52000 Bände - übernahm Springer. Sie reichten aus, den Verlust von 1506 Talern abzudecken. Den letzten Jahrgang führte Springer in eigener Regie zu Ende. Den größten Teil der Bestände natürlich mit Ausnahme der Gotthelf-Titel - verkaufte er zwei Jahre später an den Verleger Mohr in Wittenberg, der sie mit einem eigenen Titelblatt als >Neuer Haus- und Familienschatz $<$ anbot.

G otthelfs >Der Knabe des Tell<, 1845 erschienen, war Springers erstes Jugendbuch gewesen. Es wurde, wie schon Belehrung und Unterhaltung erwähnt, ein Mißerfolg. Aber nach der Revolution versuchte er sich erneut auf diesem Feld. Hermann Kletke, ein befreundeter Liberaler, war 1849 in die Redaktion der Vossischen Zeitung eingetreten und zählte wohl auch zu Springers Kunden, denn dic Zeitung hatte ihr Domizil in der Breiten Straße 8. Sein $>$ Buch der Reisen< erschien 1852 und war mit 340 Seiten sowie sechs ganzseitigen Abbildungen des fleißigen und allgemein geschätzten Theodor Hosemann illustriert. Springer hatte 4000 Exemplare drucken lassen, um das Buch zu dem relativ niedrigen Preis von 1 Taler, 10 Groschen (= 4 Mark) anbieten zu können. Die Rechnung ging auf. Drei Jahre später war die Auflage verkauft. Bei Kosten für Herstellung, Honorar und Werbung von etwa 1900 Talern konnte Springer einen Überschuß von 1625 Talern verbuchen. Das Ergebnis entsprach der damals üblichen Kalkulation, bei der etwa je ein Drittel des Ladenpreises auf den Rabatt und die Herstellkosten entfiel. Aus dem letzten Drittel mußte der Verleger seine Geschäftskosten und das Risiko bestreiten. Bei einem restlosen Verkauf der Auflage (der nicht 
31, 32: Die Titelblätter zu den beiden Jugendbüchern von Hermann Kletke zeichnete Theodor Hosemann. In Heimarbeit wurden sie koloriert.
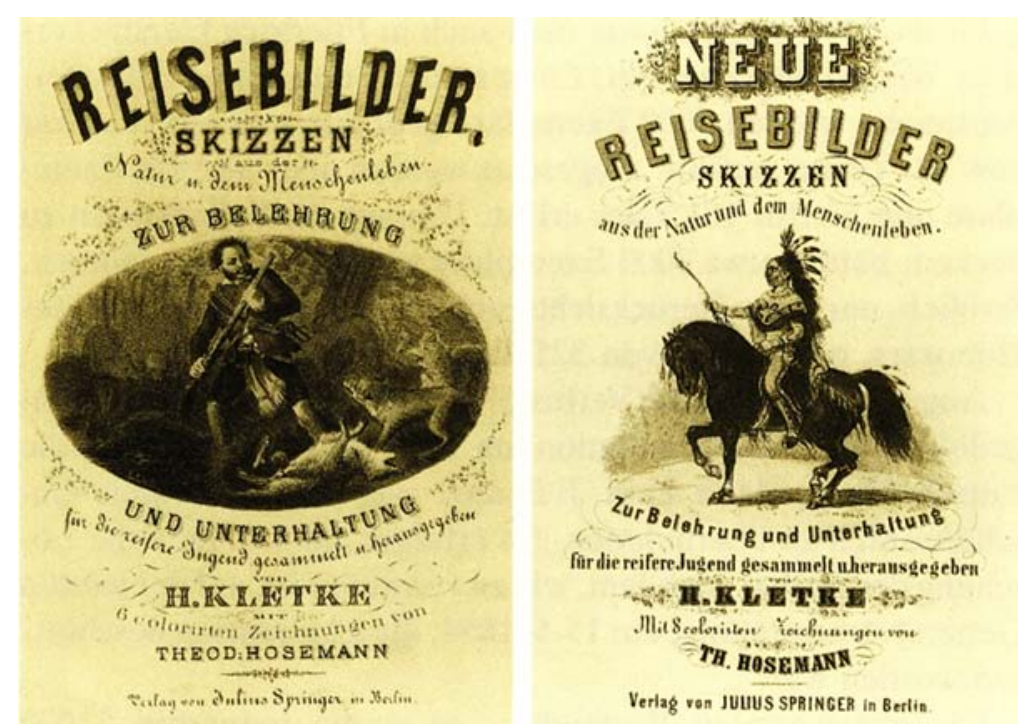

gerade häufig vorkam) verblieb ihm dann ein ansehnlicher Gewinn.

Ein Jahr später veröffentlichte Springer von Kletke ein >Neues Buch der Reisen`, ebenso umfangreich, in gleicher Weise illustriert und auch in 4000 Exemplaren gedruckt. Es war ähnlich erfolgreich. So erschienen nun Jahr für Jahr ein oder zwei Jugendbücher Kletkes >zur Belehrung und Unterhaltung für die reifere Jugend $<$. Daß die Belehrung Kletke besser gelang als die Unterhaltung, wurde später von Kritikern gerügt, aber eine solche Feststellung trifft wohl auch für andere Jugendbuchautoren dieser Zeit zu. Springer durfte mit seinem erfolgreichen Autor zufrieden sein, denn von 1852 bis 1858 veröffentlichte er immerhin elf Jugendbücher Kletkes (von zwölf insgesamt).

Ein facettenreiches Programm
$\mathrm{M}$ it schöngeistiger Literatur war Springer in den Jahren des Nachmärz (1849-1857) weitgehend erfolglos geblieben, obwohl er hierfür mehr als $60 \%$ seiner Betriebsmittel aufgewandt hatte. (Die Produktion für den Volksschriften-Verein blieb hierbei unberücksichtigt, da sie von Springer nur zu einem geringen Teil mitfinanziert worden war.)

Ertragreich waren bei der Unterhaltungsliteratur hingegen die Jugendbücher, mit denen Springer in dieser Zeit einen Überschuß von schätzungsweise $6000-8000$ Talern erzielt haben dürfte. Sie werden damit wesentlich zu einer ausgeglichenen Bilanz beigetragen haben.

Die weitere Produktion dieser Jahre belief sich, abgesehen von den Romanen, auf insgesamt 81 Titel. Hinzu kamen noch 
53 Bücher, die Springer in Kommission genommen hatte. Sie bedeuteten kein finanzielles Risiko, und jedes verkaufte Buch brachte cinen kleinen Ertrag. Diese noch recht bescheidene Produktion von insgesamt 134 Titeln in neun Jahren - wohlgemerkt ohne die Belletristik - verteilte sich auf 14 Fachgebiete.

Suchten wir nach eincr leitenden Idee für das Programm dieser Zeit, so kämen wir mit unseren heutigen Vorstellungen von einer Verlagsplanung in Verlegenheit. Richtigerweise müssen wir aber vom Verleger selbst, seinen Neigungen und von den Interessen seiner Zeit ausgehen. Probleme des Gemeinwesens lagen Springer am nächsten, und er vernachlässigte sie auch in dieser Zeit der Reaktion nicht. Sein Interesse an den öffentlichen Angclegenheiten schloß aber nicht nur dic Politik, die Wirtschaft, den Handel und Verkehr sowie soziale Fragen ein, sondern auch die Land- und Forstwirtschaft, die Chemie und die chemische Technologie, auf denen die Wohlfahrt des Staates und seiner Bürger zunchmend beruhte.

Springer verlegte Bücher, dic Bürger mit in gleicher Weise weitgespannten Interessen zum Kaufe reizen mochten, und das erfuhr er ja täglich in seiner Buchhandlung. Da er über mannigfache private und politische Kontakte verfügte, wird er auch aus Wissensdurst oder Bekennereifer manchen Gesprächspartner zur Abfassung eines Buches oder einer Broschüre bewogen haben. So sollten wir uns also über das bunte Nebeneinander in seinem Programm nicht zu sehr wundern. In dieser Vielfalt unterschied sich Springers Verlag kaum von dem seiner großen
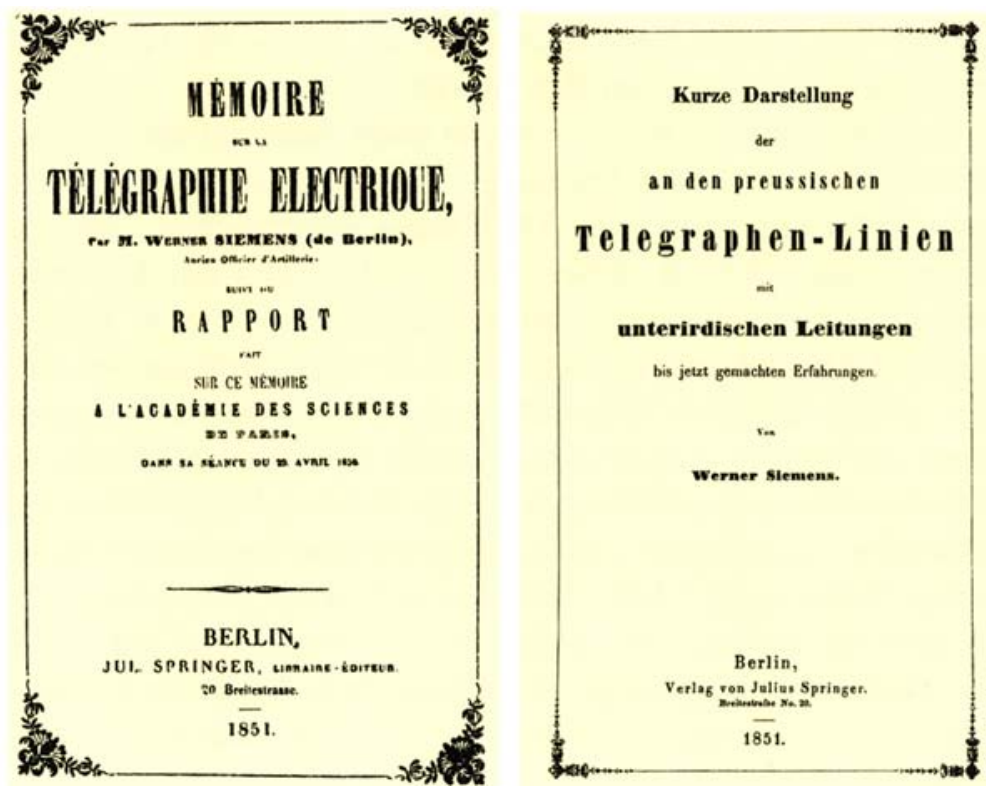

33, 34: Siemens legte seinen Bericht am 29. April 1850 der Pariser Akademie der Wissenschaften vor. Die Druckausgabe erschien schon im Spätsommer 1850 (vordatiert auf 1851). Alexander von Humboldt hatte die zunächst erschienene französische Ausgabe »mit sehr, sehr großem Interesse" gelesen und Siemens - »teuerster Herr Leutnant « zu einer Konversation um die Mittagszeit eingeladen. 
35: Julius von Kirchmann (1802 bis 1884) war seit 1846 Erster Staatsanwalt beim Berliner Kriminalgericht. Seine der Regierung nicht genehmen Urteile und sein publizistisches Wirken führten schlieglich 1867 zur Entlassung aus dem Staatsdienst. Außer Kirchmanns juristischen und philosophischen Schriften veröffentlichte Springer auch die Prozeßakten, die zu Kirchmanns Amtsenthebung gefuhrt hatten.

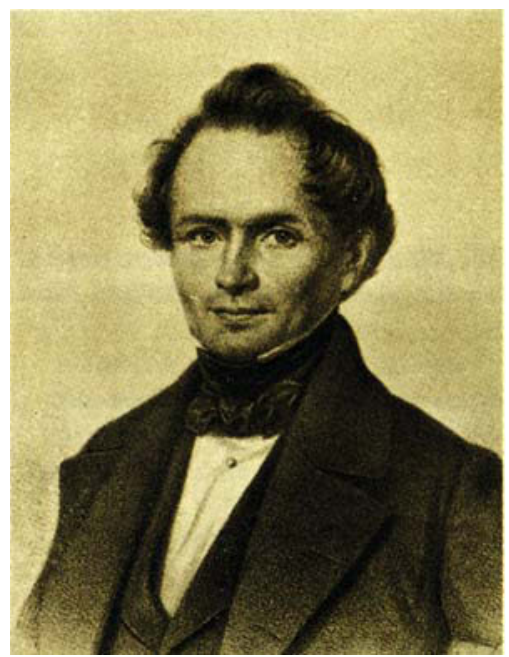

Kollegen Brockhaus, Cotta oder Campe, deren Programm in dieser Zeit nicht weniger gemischt war. (Und sind nicht auch die Programme mancher heutiger Verlage oft in gleicher Weise scheinbar disparat?) Nur überwogen bei Springer noch Schriften von geringerem Umfang, dic ein entsprechend niedrigeres Risiko bereiteten: 68 Bücher hatten weniger als 100 Seiten Umfang, davon 42 weniger als 50 Seiten.

Es ist auch zu bedenken, daß dic Interessen der >Gebildeten $<-$ und nur sie konnten sich Bücher leisten oder waren bereit, sich hierfür in anderen Lebensbereichen einzuschränken - weiter gespannt waren als in unserer Zeit. Der kritische Bürger, mochte er nun demokratisch, liberal oder konservativ orientiert sein, nahm ebenso Anteil an Zoll- und Handelsfragen wie an den Naturwissenschaften oder der Geschichte. So wurden seit 1842 Liebigs > Chemische Briefe $<$ in Cottas >Morgenblatt für gebildete Leser v von einem breiten Publikum gelesen. Das Interesse war so lebhaft, daß die Briefe fortgeführt und bald auch in Buchform ediert und in viele Sprachen übersetzt wurden. Und Alexander von Humboldts >Kosmos` gilt, nach der Bibel, allgemein als das meistgelesene Buch der 40er und 50er Jahre [LOHRER: 102].

Solche Beispiele gibt es auch in Springers Programm: Als Werner Siemens am Vorabend der Revolution seinen Zeigerund Drucktelegraphen erfand und eine erste unterirdische Leitung verlegte, war dies ein Gesprächsstoff »in den höheren Gesellschaftskreisen Berlins« [SiEmens: 46]. So ist auch sein Vortrag, den er am 28.4.1851 vor der > Académie des Sciences< in Paris hielt, durchaus noch für ein breiteres Publikum gedacht. Springer brachte das Buch noch im selben Jahr in deutscher und französischer Sprache auf den Markt.

Auch dic Autoren waren zumeist noch nicht auf ein >spezialisiertes $<$ Fachpublikum festgelegt. Der Jurist Julius Hermann von Kirchmann hatte z.B. 1847 seine unverzüglich zweimal nachgedruckte Schrift >Über die Werthlosigkeit der Jurisprudenz als Wissenschaft $<$ bei Springer erscheinen lassen. In den $60 \mathrm{er}$ und 70er Jahren veröffentlichte er >Erinnerungen aus Italien<, eine Schrift über > Die Reform der evangelischen Kirche in Lehre und Verfassung und eine andere über parlamentarische Debatten. Seine fast 600 Seiten starke >Philosophie des Wissens (1864) war das umfangreichste philosophische Buch in Springers Verlag. ${ }^{10}$ Hermann Kletke verfaßte neben Kinderbüchern für ihn auch historische und geographische Werke und gab - für einen anderen Verlag - eine > Volksbibliothek deutscher Klassik < heraus. Autoren und Leser waren noch universeller orientiert als heute. 
$\mathrm{D}$ cutlichere Ansätze zu einer Spezialisicrung werden in deutschen Verlagen erst seit der Jahrhundertmitte erkennbar. Erste Titel fachspezifischen Inhalts bemerken wir im Programm Springers schon unmittelbar nach der Revolution. So begann er 1849 mit der Herausgabe von >Chemisch-technischen Mitteilungen<, die zunächst alle zwei Jahre, seit 1857 dann jährlich erschienen. Ebenfalls 1849 veröffentlichte er von Louis Müller ein Buch über > Die Fabrication des Papiers, in Sonderheit des auf der Maschine gefertigten, nebst gründlicher Auseinandersetzung der in ihr vorkommenden chemischen Processe...<, das schon nach kurzer Zeit vergriffen war. Bei der 2. Auflage, die auf das Doppelte erweitert wurde, konnte Springer einen Überschuß von 382 Talern verbuchen, der natürlich noch seine Geschäftskosten decken mußte. Der Autor bekam ein Honorar von 60 Talern, nach Deckung der Kosten ein zweites in gleicher Höhe. Bei der 4. Auflage (1877) betrug der Umfang schon 450 Seiten. 1850 gab Müller ein >Lehrbuch der Chemie heraus, von dem aber nur eine Lieferung erschien.

Zu einem Erfolgstitel für viele Jahrzehnte und zur Keimzelle eines späterhin sehr bedeutenden Verlagszweigs wurde der 1851 erstmalig erschienene >Forst- und Jagdkalender für Preußen<, den Friedrich Wilhelm Schneider, Professor an der Königlich Preußischen Forstlehranstalt in Eberswalde, herausgab. Zwar hatte Springer zunächst nur den Vertrieb für Preußen - bei weitem also das Hauptabsatzgebiet -, doch die Überschüsse konnten sich sehen lassen, zumal die Auflage von Jahr zu Jahr stieg.

In der Programmgruppe >Wirtschaft, Verkehr, Handel und Soziales< veröffentlichte Springer jährlich zwei bis drei Titel, doch überwogen zunächst noch Kleinschriften, die er lediglich in Kommission übernahm. Fragen der Gewerbeordnung, der Zölle oder des Bankwesens interessierten ihn zwar sehr, doch

Neue Akzente

\author{
Newe Akzente
}




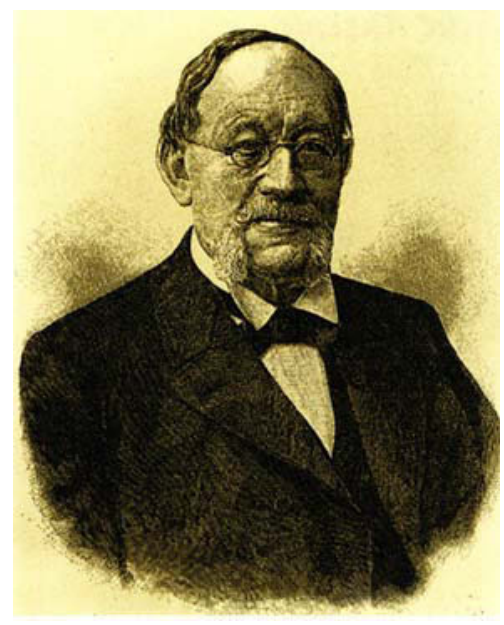

37: Der Staatsrechtler Rudolf Gneist (1816-1895), ein Schüler von Friedrich Karl von Savigny. Bei Springer erschienen 28 seiner zum Teil sehr umfangreichen Bücher.

Verkauf der Buchhandlung von einer Spezialisierung kann in diesem Bereich noch nicht die Rede sein. Dies alles sind erste Ansätze, aus denen sich später eigene Verlagszweige entwickelten. Der fachlich Interessierte wird im systematisch gegliederten Verlagskatalog manche Entdeckung machen können.

Auf dem Gebiet der Innenpolitik mußte sich Springer nach seinen Querelen mit der Zensur wohl zurückhalten, doch es gab neben Wirtschaftsfragen auch Probleme in der Außenpolitik: Der Krimkrieg (1853-1855), die Orientfrage, das unter Napoleon III. politisch und wirtschaftlich erstarkende Frankreich oder die englische Verfassung fanden allgemeines Interesse. Gerade in solchen Büchern ließen sich Ideen vertreten und auf die deutschen Verhältnisse übertragen, deren direkte Ansprache, z.B. die Verfassungsfrage, zu dieser Zeit ja nicht möglich war. Rudolf Gneists >Das heutige englische Verfassungs- und Verwaltungsrecht < erschien 1857 mit ihrem ersten Band von über 700 Sciten. Gneist war der profilierteste Staatsrechtler seiner Zeit; Springer hatte ihn als Fraktionskollegen im Berliner Stadtrat kennengelernt.

\footnotetext{
$\mathrm{D}$
} as Sortiment hatte sich auch nach der Märzrevolution weiter gut entwickelt, und Springer war von der im Buchhandel allgemein als schlecht empfundenen Geschäftsentwicklung offenbar weniger betroffen als andere Firmen: Am 29.7.1853 konnte er Gotthelf von einer Vergrößerung seiner Geschäftsräume in der Breiten Straße berichten. Er verfüge nun über fünf Räume, »dabci cin Comptoir nur für mich, wo ich auch die Herren Autoren empfange«.

Die zeitlichen Belastungen durch das Sortiment, das Kommissionsgeschäft und den Verlag hatten im Laufe der Jahre ständig zugenommen, denn jeder Unternehmenszweig entwikkelte eine eigene Dynamik. Die wachsenden Aufgaben gingen bald über Springers Kräfte: »Ich bin jetzt kein Mensch mehr «, hatte er schon am 21.4.1852 an Gotthelf geschrieben; cr arbeite von morgens um acht bis abends elf Uhr, denn die Produktion nahm ständig zu: Waren jährlich zunächst etwa 10 bis 15 Titel in seinem Verlag erschienen, so stieg die Zahl der Veröffentlichungen 1856 und 1857 auf 25 bzw. 32 Titel.

Um die Wirtschaft war es nicht gerade gut bestellt. Europa spürte 1857 die Auswirkungen einer Wirtschaftskrise, die in den USA ausgebrochen war. Geld war nur noch zu stark überhöhten Zinsen zu beschaffen. In dieser Situation wird es für Springer die beste Entscheidung gewesen sein, sich von seinem Sortiment und dem Kommissionsgeschäft zu trennen, auch wenn es ihm 
gewiß nicht leicht fiel, »sein selbst gegründetes, mit Liebe und Sorge gepflegtes Geschäft « in andere Hände zu geben [MS: 53]. »Sechzehn Jahre habe ich das 1842 hier gegründete Détailgeschäft geführt «, schreibt er am 7.6.1858 an Henriette Gotthelf. »Die tausend kleinen Mühen und Sorgen desselben haben mich so vollständig in Anspruch genommen, daß ich in der Tat in dieser ganzen Zeit den Meinen und der Familie wenig angehörte. Nachdem nun mein eigener Verlag bedeutender geworden, fühle ich, daß es mir mit der Zeit, schon physisch, unmöglich werden dürfte, beide Teile des großen Geschäftes mit der Energie und Ausdauer fortzuführen, die zu deren Gedeihen notwendig sind.«

Sein Entschluß mag ihm durch den Umstand erleichtert worden sein, daß die Trennung von bisher gemeinsam geführten Sortiments- und Verlagsfirmen in jenen Jahren durchaus üblich war; die Spezialisierung lag im Zuge der Zeit. Sie war die Folge der sich nun immer unterschiedlicher entwickelnden Geschäftszweige. $1857 / 58$ trennten sich allein in Berlin außer Springer noch Alexander Duncker, die Nicolai'sche Buchhandlung und Dietrich Reimer von ihrem Sortiment.

Ein Kaufinteressent für eine Buchhandlung in so günstiger Lage mit guter Stammkundschaft fand sich relativ rasch. Der

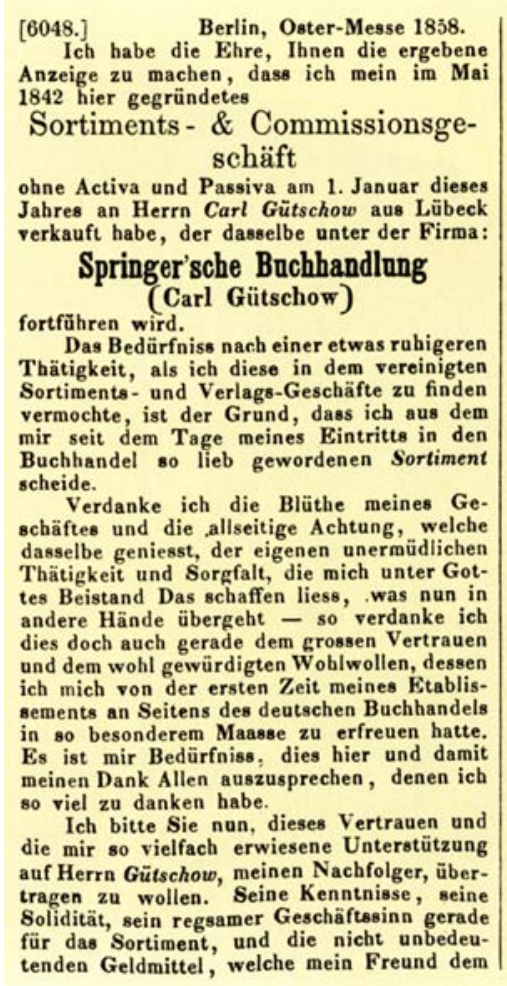

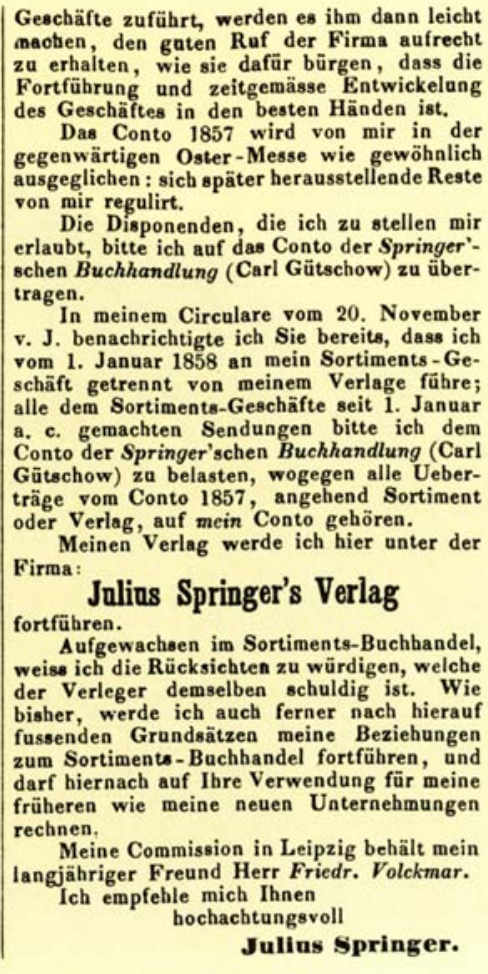

Geschäfte zuführt, werden es ihm dann leicht maotien, den gaten Ruf der Firma aufrech zu erhalten, wie sie dafür bürgen, dass die des Geschäftes in den besten Händen ist. Das Conto 1857 wird von mir in der gegenwärtigen Oster-Messe wie gewöhnlich ausgeglichen : sich später herausstellende Reste mir regulirt.

erlaubt, bitte ich auf das Conto der Springer'schen Buchhandlung (Carl Gütschow) zu überragen. reits, dass ich vom 1. Januar 1858 an mein Sortiments - Geschäft getrennt von meinem Verlage fübre; lle dem Sortiments-Geschafte seit 1. Januar Conto der Springer'schen Buchhandlung (Carl Gütschow) za belasten, wogegen alle Ueberoder Verlag, auf mein Conto gehören. fortführen.

ufgewachsen im Sortiments-Buchbandel, weiss ich die Rücksichten zu würdigen, welche der Verleger demselben schuldig ist. Wie fussenden Grundsätzen meine Beziebungen zum Sortiments - Buchbandel fortführen, und darf hiernach auf Ihre Verwendung für meine früheren wie meine neuen Unternehmungen chnen,

Meine Commission in Leipzig behält mein
langähriger Freund Herr Friedr. Volckmar.

Ich empfehle mich Ihnen

Julius Springer.
38: Als Springer sein Sortiment verkaufte - hier die Anzeige aus dem Börsenblatt -, soll der Berliner Verleger Alexander Duncker (1813 bis 1892) geäußert haben: „Springer ist der geborene, befähigste Sortimenter; wird er ein gleicher Verleger sein? Er stand auf der ersten Stufe der Sortimentsbuchhandlungen und wird nun ein Verleger zweiten oder dritten Ranges! « [MS: 54]. Später gab Duncker seine Fehleinschätzung freimütig zu. 
aus Lübeck stammende Carl Gütschow erwarb Sortiment und Kommissionsgeschäft zu einem für Springer recht vorteilhaften Preis, und dieser fand »eine besondere Freude darin, es einem ebenbürtigen Nachfolger « übergeben zu können, schreibt seine Frau in ihren Erinnerungen [MS: 53]. Aber Springer war vorsichtig: Am 23.12.1857 teilte er im Börsenblatt zunächst nur die rechnungsmäßige Trennung von Verlag und Sortiment ab dem 1.1.1858 mit. Den neuen Inhaber erwähnte er noch nicht. Dies geschah erst in einem Circular, das er zur Ostermesse 1858 verschickte und in dem sich Gütschow nun auch selbst dem Buchhandel vorstellte, und, wie üblich, auch die Zeugnisse seiner früheren Prinzipale abdrucken ließ. Springer hatte offenbar eine gute Wahl getroffen, und der Nachfolger hatte sich wohl schon im ersten Vierteljahr bewährt. ${ }^{11}$

Als Gütschow eingearbeitet und mit der Kundschaft bekanntgemacht war, übersiedelte Springer am 4.8.1858 mit seinem Verlag zum Monbijouplatz 3 in das Haus seines 1845 verstorbenen Schwiegervaters. Der Platz lag unmittelbar bei dem gleichnamigen Schloß. Georg Ferdinand Oppert, Marie Springers Vater, hatte das dreigeschossige Wohnhaus 1830 gebaut, in das Julius Springer mit seiner Familie schon im Sommer 1853 eingezogen war.

39: Das Haus am Monbijouplatz lag in einer ruhigen Wohngegend, doch die Innenstadt lag nahe; in nur 15 Minuten war man Unter den Linden. Dieses Domizil diente dem sich stetig über das ganze Haus ausbreitenden Verlag bis zum Jahre 1911, also reichlich ein halbes Jahrhundert, als Arbeitsstätte. Die Beletage wurde noch einige Jahre nach dem Tod Julius Springers von seiner Witwe bewohnt. Nach deren Auszug 1889 wurde das ganze Stockwerk in ein Großraumbüro umgewandelt (Aufnahme aus dem Jahr 1867).

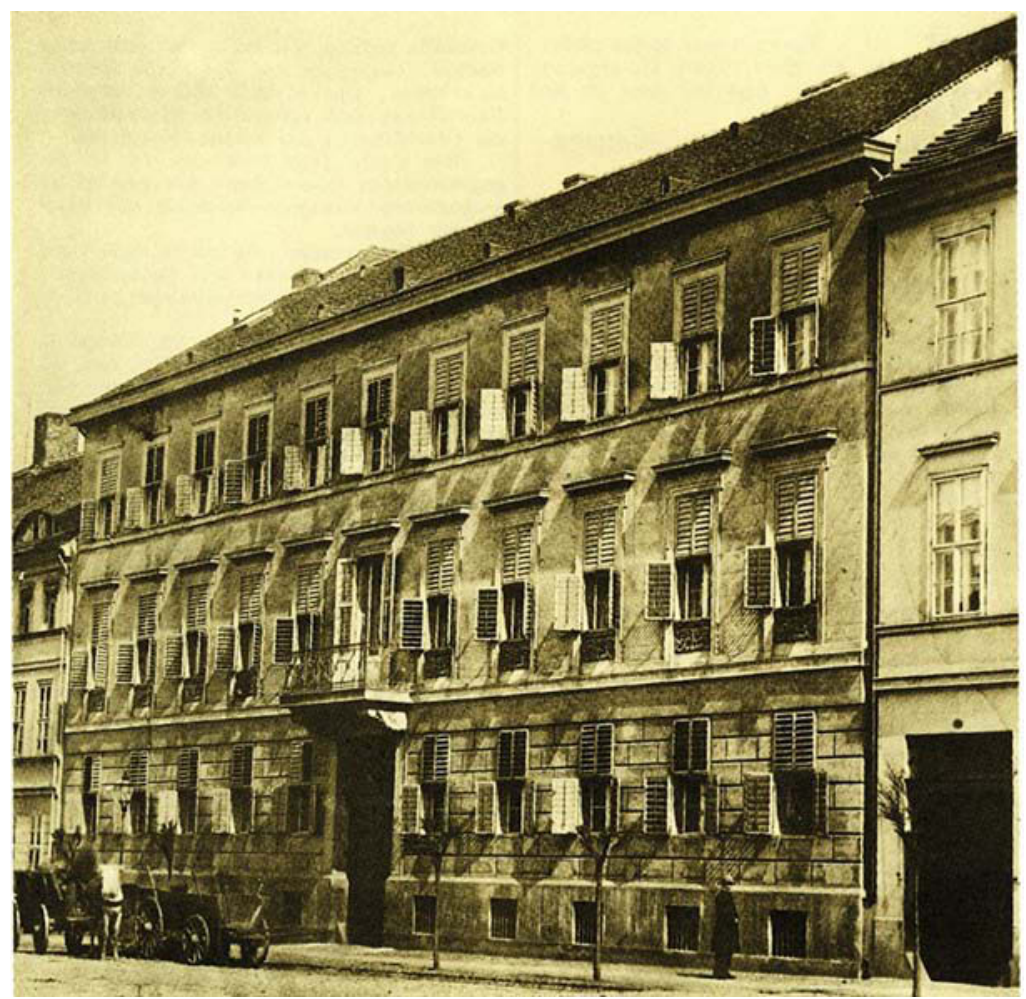

